\title{
Consumer Perception and Preference towards Genetically Modified (GM) Foods: Bibliometric Evidence and Policy Imperatives
}

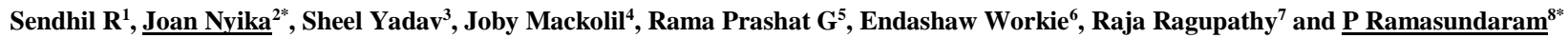 \\ ${ }^{1}$ ICAR-Indian Institute of Wheat and Barley Research, Karnal, INDIA. \\ ${ }^{2}$ Technical University of Kenya, Nairobi, KENYA. \\ ${ }^{3}$ ICAR-National Bureau of Plant Genetic Resources, New Delhi, INDIA. \\ ${ }^{4}$ CHRIST (Deemed to be University), Bangalore, INDIA. \\ ${ }^{5}$ ICAR-Indian Agricultural Research Institute, New Delhi, INDIA. \\ ${ }^{6}$ School of Environmental science and Engineering, Shanghai Jiao Tong University, Shanghai, CHINA. \\ ${ }^{7}$ Lethbridge Research and Development Centre, Agriculture \& Agri Food Canada, Alberta, CANADA. \\ ${ }^{8}$ National Agricultural Higher Education Project, Indian Council of Agricultural Research, New Delhi, INDIA. \\ * Corresponding author
}

\section{Background}

Genetically modified (GM) foods could be a promising option to reduce the dependence of the agrifood system on conventional means of crop improvement. However, the safety of GM food remains a concern, in addition to the perceived and real risks to environment. The opinion about scientific evidence among researchers, policymakers and government regulators on promotion of GM foods for consumers differ. This study presents the trends emerging from research outputs on consumer perception and preference for GM foods and policy prescriptions for enabling the consumption.

\section{Scope and Approach}

The study mainly focused on (1) exploring the publication trends, geographic focus of research and a comprehensive review on the consumers' perception of and preference to GM foods, (2) identifying research hotspots and emerging genetically modified organisms (GMO) research themes, (3) assessing the integrated nature of GMO research, and (4) suggesting policy prescriptions on challenges and way forward. Bibliometric analyses have been performed using the Web of Science (WOS) database sourcing literature from 1981 to 2021 and analyzed the final sample of 543 publications using BibExcel and VOSviewer visualization software tools. The search strategy utilized the topic basis search of phrases related to GM food preference and perception.

\section{Key Findings and Conclusions}

The search query retrieving 543 journal articles showed an increasing trend in publications on consumer's response towards GM foods. Thematic analysis revealed a strong interlinkage of GMOs research with 'agriculture' and 'food science technology'. Consumers' positive response is largely influenced by the decision of the governments to ban or approve the GM crops cultivation. Similarly, the public support increases when the potential benefits of the technology are well articulated, consumption increases with a price discount, people's trust on the government and belief in science increases with a positive influence by the media. Mapping of the retrieved articles showed the top four recurrent keywords: GMOs, biotechnology, attitudes and acceptance. Europe and the USA are the first region and country, respectively, in terms of the number of active institutions per research output, per capita GDP publication and citations per article. The National Natural Science Foundation of China, followed by the National University of Malaysia are the top fundraisers for research on GM food consumption, perceptions and attitudes. Although research outputs on GM food consumer's acceptance and preferences are increasing, a majority of publications came from developed nations. Thus, intensive research is yet to be carried out in developing countries to produce a genetically modified food product with superior properties and substantial equivalence with no significant side-effects. We suggest research-, agri-food industries-, and society-oriented policies needed to be implemented by the stakeholders to ensure the safety of GM food products, encourage consumer-based studies, and increase public awareness towards these food products.

Key words: Bibliometric analysis; Consumer perception; Consumer preferences; GMOs; GM food; Industry implications; Policy imperatives; Future research thrust. 


\section{Graphical Abstract}

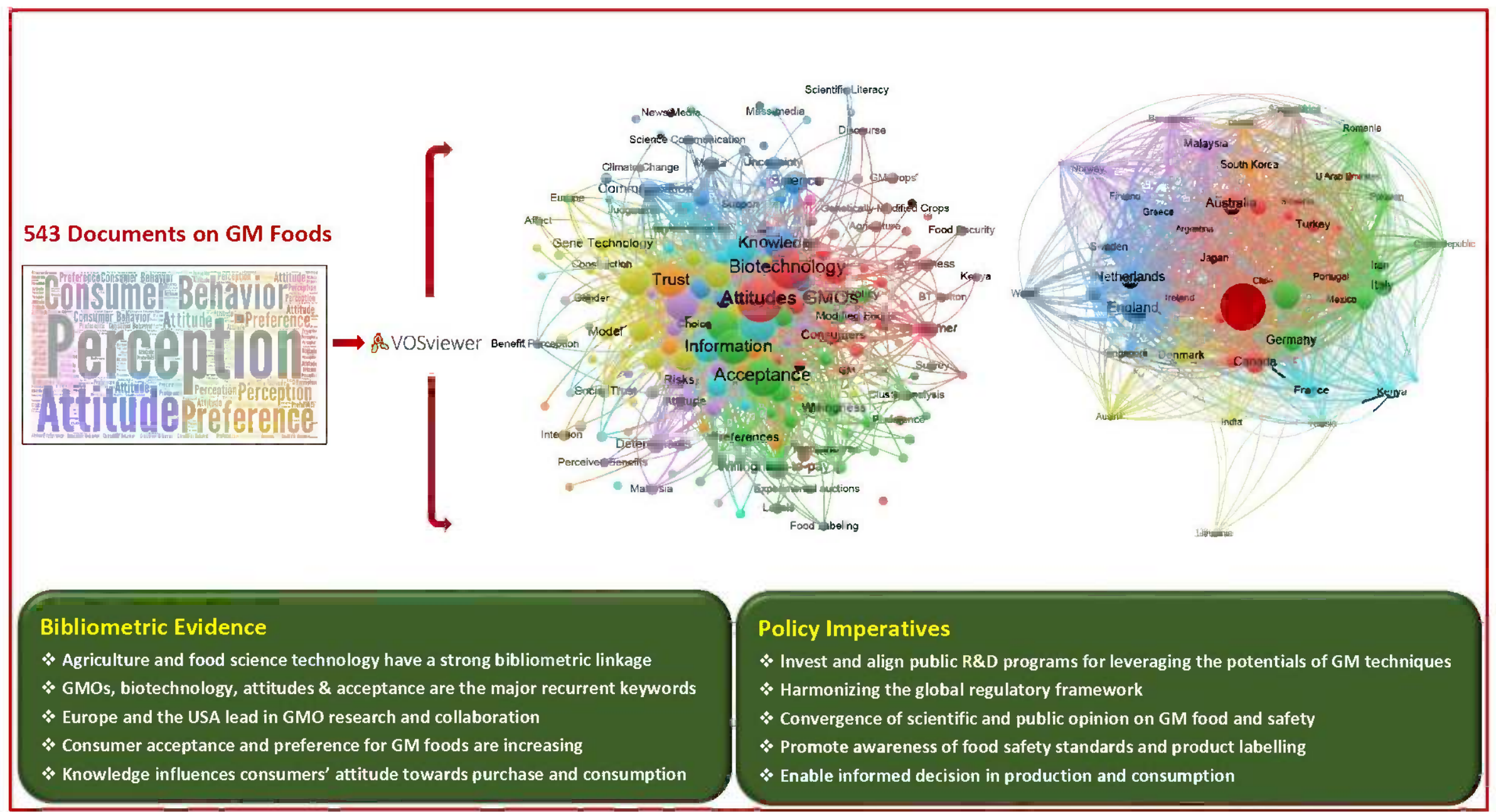

Page 1 of 42 


\section{INTRODUCTION}

Feeding the burgeoning population, estimated to reach 11 billion by $2100 \mathrm{AD}$, will undoubtedly be a herculean task (Szenkovics et al., 2020). It is estimated that a vast majority of this population growth will occur in developing countries, home to more than two-thirds of those suffering from hunger. The Food and Agriculture Organisation (FAO) estimated that 653 million people were undernourished in 2015 and the number rose to 690 million in 2019. It is expected that the number will continue to rise hence the difficulty in realizing an end to hunger and malnutrition by 2030 (FAO, 2020). Timely policy intervention is required to liberate these economies from the shackles of hunger and poverty. With the finite arable land being exposed to high rates of soil and water degradation, cultivation of our future crops will be increasingly challenging. Sustainable food production under such circumstances, demands agricultural scientists across the globe to develop improved cultivars with enhanced productivity using modern tools of plant- breeding, production and protection. It is through the scientific efforts and farmer's endeavours, that the annual average increase in yields to the tune of 1.2 per cent has been achieved for the four staples, i.e., wheat, rice, maize and soybean, which together contribute to 66 per cent of calorie intake in the global diet (Oliver, 2014). This gain in yield still is lower than the normative growth rate of 2.4 per cent per annum required to support the predicted global population (Raman, 2017). What lies ahead is a tumultuous path with challenges like climate change with frequent extreme weather events, emergence of new pests and diseases, etc. This necessitates a multi-pronged strategy aiming at development of cultivars with increased productivity which are climate resilient, nutritionally superior, resistant to biotic stresses and leave a reduced 'carbon' footprint on the environment.

Crop improvement based on scientific principles dates back to the $18^{\text {th }}$ century. The significant role of breeders during the 1960s, in improving the productivity was very crucial one. The era of 'green revolution' heralded the emergence of hybridization and selective breeding, as drivers 
for enhancing food production through the development of high yielding semi-dwarf varieties, tailored for new mechanized cultivation practices and responsive to synthetic fertilizers that replaced low yielding multi crops with high yielding mono crops. However, conventional breeding has a major limitation in terms of utilizing genes from tertiary gene pools due to barriers arising from reproductive isolation. This is where GM technology, along with markerand genomics- assisted crop improvement, strengthened accomplishment of sustainable global food security. GMO technologies offer a much wider scope, allowing gene introgression, overcoming the reproductive barriers defining the species. The World Health Organization (WHO) defines "genetically modified organisms (GMOs) as organisms (i.e. plants, animals or microorganisms) in which the genetic material (DNA) has been altered in a way that does not occur naturally by mating and/or natural recombination". The foods which are derived from GM organisms are often referred to as GM foods. Since the development of the first transgenic plant for agriculture in 1983, the GMO technology has grown by leaps and bounds. These are cultivated across 26 countries on a global area of 191.7 million hectares (ISAAA, 2018). The three most common traits found in GM crops include herbicide tolerance, resistance to insects and plant viruses. The top five biotech crops grown are soybean, maize, cotton, canola and alfalfa driven by commercial farming and commodity values. For maize, as high as 137 transgenic events have been approved in over 35 countries (ISAAA Brief 54, 2020). Countries like the USA, Argentina and Canada are the major producers and exporters of GM crops and products (James, 2011; https://www.isaaa.org/). Owing to the phenomenal increase in area under GM crops, this technology has been claimed to have become the fastest adopted crop technology in the world, with a 113-fold increase from 1996. However, the expansion in production and commercialization of GM crops has not been smooth, and was impeded with protests and bans by many governments worldwide, due to recommendations by various national regulatory bodies. While the impact of GM foods in enhancing crop productivity 
cannot be overlooked, a large section of the society remains wary of the same. The reasons for this apprehension are many, some of which are the potentially adverse impact of GM food crops on human health and environment, lack of public awareness, lack of independent and credible scientific studies on risk assessment, policy bottlenecks, etc. Lack of consensus among the scientific community regarding the environmental and food safety issues is another major concern. There are several issues that have been intensely debated in many public and academic forums. The most prominent of these issues is the likelihood of gene flow to the wild and weedy relatives rendering them more aggressive, allergenicity in humans due to the new protein synthesized in the GM food crop, monopolisation in food supply and vertical restraint, which defeats the very idea of consumer welfare (Munro, 2003). The safety of GM food for human consumption remains a topic of debate amongst scientists, policy makers and consumers. To allay the fears arising due to the presence of antibiotic selectable marker genes which have been feared to lead to the evolution of "superbugs" through horizontal gene transfer, a great deal of research has been undertaken towards the development of transformation methods which are marker-free and strategies for selectable marker elimination through homologous recombination, transposition, etc., have been developed.

Due to differences in consumer responsiveness towards GM food crops, the regulatory framework adopted by different countries for their release and commercialization are significantly different. While countries like the USA and Canada, adopt a more flexible and receptive outlook towards the GM food crops, countries in Europe are more opposed when it comes to the environmental release of GM food crops. The approach of the US for regulation of GMOs is based on the supposition that regulation should focus on the nature of the products (product based), rather than the process involved in the production (Zetterberg \& Bjornberg, 2017). In order to address the concerns raised by the consumers, different labelling requirements are in place, in different countries. While the US Food and Drug Administration 
(FDA), does not require labelling of GM foods unless the transgenic food is substantially different from its conventional counterpart, the EU, by contrast, mandates the labelling of all foodstuffs, additives and flavours, containing 1 per cent or more genetically modified material (Regulations 1139/98 and 49/2000; Watson, 2019). India is still waiting for its first GM food crop ( $B t$ brinjal) to be commercialized. It has been put on an indefinite moratorium since 2010 . This casts shadows of uncertainty on the fates of many GM crops, food and non-food crops which are at different stages of development in the laboratories and field trials for release.

Owing to the different policies adopted for regulation of GM food across the world, there are large perceivable differences in the research and developmental activities. This is demonstrated in terms of differences in the number of publications emerging from different countries with regard to GM food, the active involvement of funding agencies in facilitating the research and developmental activities, etc. There are several such parameters which can be analysed to understand the global perception of these crops and these can potentially serve as indicators to predict their future. Even though a large number of review articles is available where the authors have very diligently described the GMO technology and its pros and cons, the scientific, economic, environmental and cultural impact, an analysis of the vast amount of this information, in terms of bibliometric studies is rarely found. Similar analysis has been recently used to assess the research patterns concerning various health related topics such as incidence of diseases like malaria, tuberculosis (Sweileh et al., 2016); medical data analysis (Liao et al., 2018), etc. Considering the plethora of literature available on this topic, a bibliometric visualization analysis will allow assessment of the current research activities with regards to GM food development, estimation of relative contribution of different countries and will shed light on future developmental trajectories in this area. 


\section{CONCEPTUAL DESIGN AND METHODOLOGY}

GMO, despite being one of the fastest adopted technologies due to its scientific, economic and environmental merits, has faced opposition owing to the diverse regulatory mechanism arising from political ideologies and cultural perceptions leading to road blocks in universal consumer acceptance. The present study has been conceptualised to capture the bibliometric evidence of perception and consumer preference towards GM food using a visualization tool, its potential benefits to various stakeholders, opportunities and challenges followed by policy prescriptions for all researchers, stakeholders including agri-industries, producers and consumers (Fig. 1).

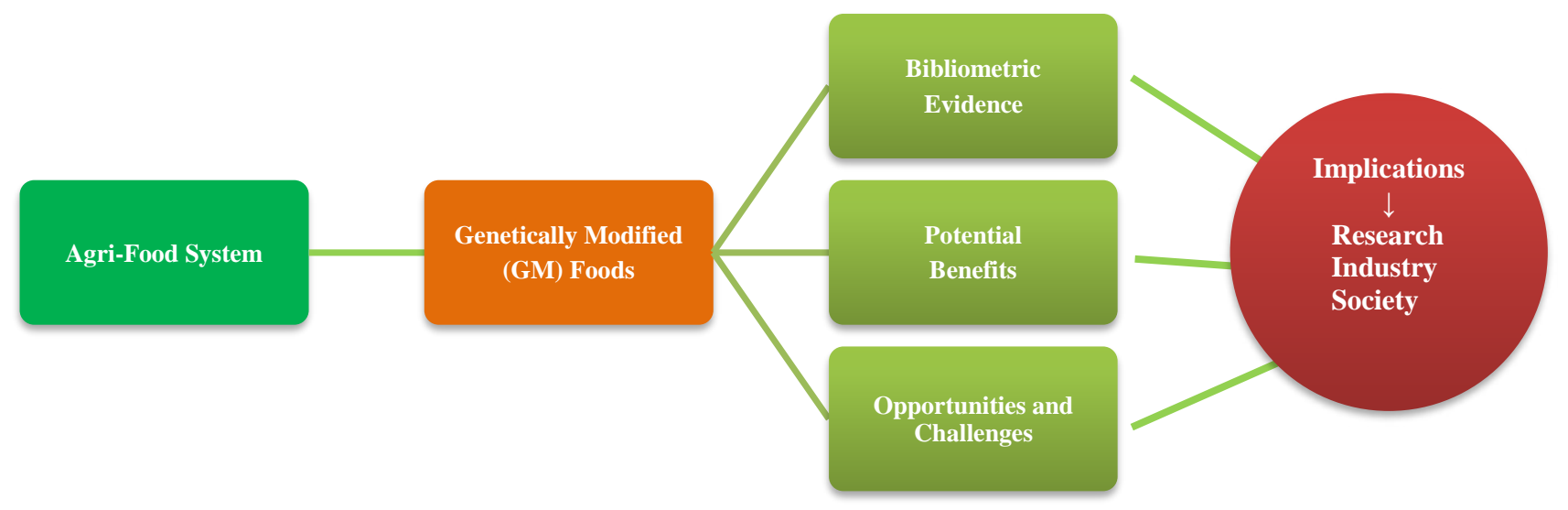

Figure 1: Conceptual design of the study

\subsection{Database Selection}

The Web of Science (WOS) database was used to retrieve relevant articles and data. Several advantages of WOS make it suitable for bibliometric analyses. It is one of the most widely used databases for searching publications and has a more consistent coverage of publications dating back to 1900. Besides, searches done on the database are robust, not limited to English language and in addition, include details of authors, citations, open access options and funding agencies 
(Chadegani et al., 2013). The database also gives access to archived information from journals according to Mongeon and Paul-Hus (2015).

\subsection{Search Strategy}

One of the pre-conditions of scientometric analysis is coming up with a good search query of high validity for comprehensive results and analysis. This study developed queries on the topic of GM food by doing a pre-review of both grey literature and scientific publications to compile some search phrases as advised by Sweileh and Mansour (2020) who conducted a bibliometric analysis on environmental antimicrobial resistance. Four study scenarios joined by the Boolean operator "or" were used. The specific searches were "perceptions on genetically modified food" or "attitudes towards genetically modified food" or "preference rates of genetically modified food" or "consumer behaviour towards genetically modified food". The options were searched on topic basis.

\subsection{Refining Results Retrieved from the Search}

Total documents retrieved were 616 consisting of 543 research articles $(88.15 \%), 36$ reviews (5.84\%), 16 proceeding papers $(2.60 \%), 10$ early access $(1.62 \%), 7$ editorial material (1.14 $\%), 3$ book chapters $(0.49 \%), 1$ meeting abstract and news item each $(0.16 \%)$. The crosschecking of the searched results through screening and eligibility analysis for missing data or false negatives led to exclusion of 28 and inclusion of 588 documents. The further search restricted to exclusively journal articles to focus more on original research, resulted to 543 journal articles, used for the final bibliometric analysis. The study period was 1981 to 2021, though initial evaluations showed limited research before the year 2000. Language restrictions were not imposed. The flow of bibliometric search is given in Appendix 1. 


\subsection{Data Export and Analysis}

Retrieved data were transferred from WOS to Microsoft Excel for tabular and graphical representation. The VOS viewer software was used to create the visualization maps (Van Eck \& Waltman, 2011). Using the link strengths from the maps, different inter-relationships of the articles, countries and institutions of their origin, co-citations and authors were represented. A thicker connecting line and a higher value for the link corresponded to a stronger correlation of the aspect of evaluation (Van Eck \& Waltman, 2011). Several bibliometric indicators used in this study include: 1) growth in publication in the evaluation period, 2) research themes relevant to the search query, 3) most active journals, funding agencies, institutions and countries and 4) co-citations.

\section{BIBLIOMETRIC EVIDENCE}

\subsection{Features of Publications Retrieved}

On inputting the search query in the WOS database, 543 journal articles were retrieved that constituted the majority of the document type at 88.15 per cent. While the majority of the articles was written in English $(n=525 ; 96.7 \%)$, the rest were written in Spanish $(n=6 ; 1.1 \%)$, Lithuanian $(n=3 ; 0.6 \%)$, German $(n=2 ; 0.4 \%)$, Czech $(n=1 ; 0.2 \%)$, French $(n=1 ; 0.2 \%)$, Indonesian $(\mathrm{n}=1 ; 0.2 \%)$, Malay $(\mathrm{n}=1 ; 0.2 \%)$, Polish $(\mathrm{n}=1 ; 0.2 \%)$, Portuguese $(\mathrm{n}=1 ; 0.2 \%)$ and Russian $(\mathrm{n}=1 ; 0.2 \%)$. About $29 \%(\mathrm{n}=156)$ of the total retrieved journal articles were available as open access to the readers.

\subsection{Annual Growth in Publications}

The incremental growth in the searched area of GM food perceptions, attitudes, preferences and consumer behaviour was on a rising trend based over the past five years (Figure 2), compared to the period 1990 - 2005 when the number of publications recorded on the topic was limited. 


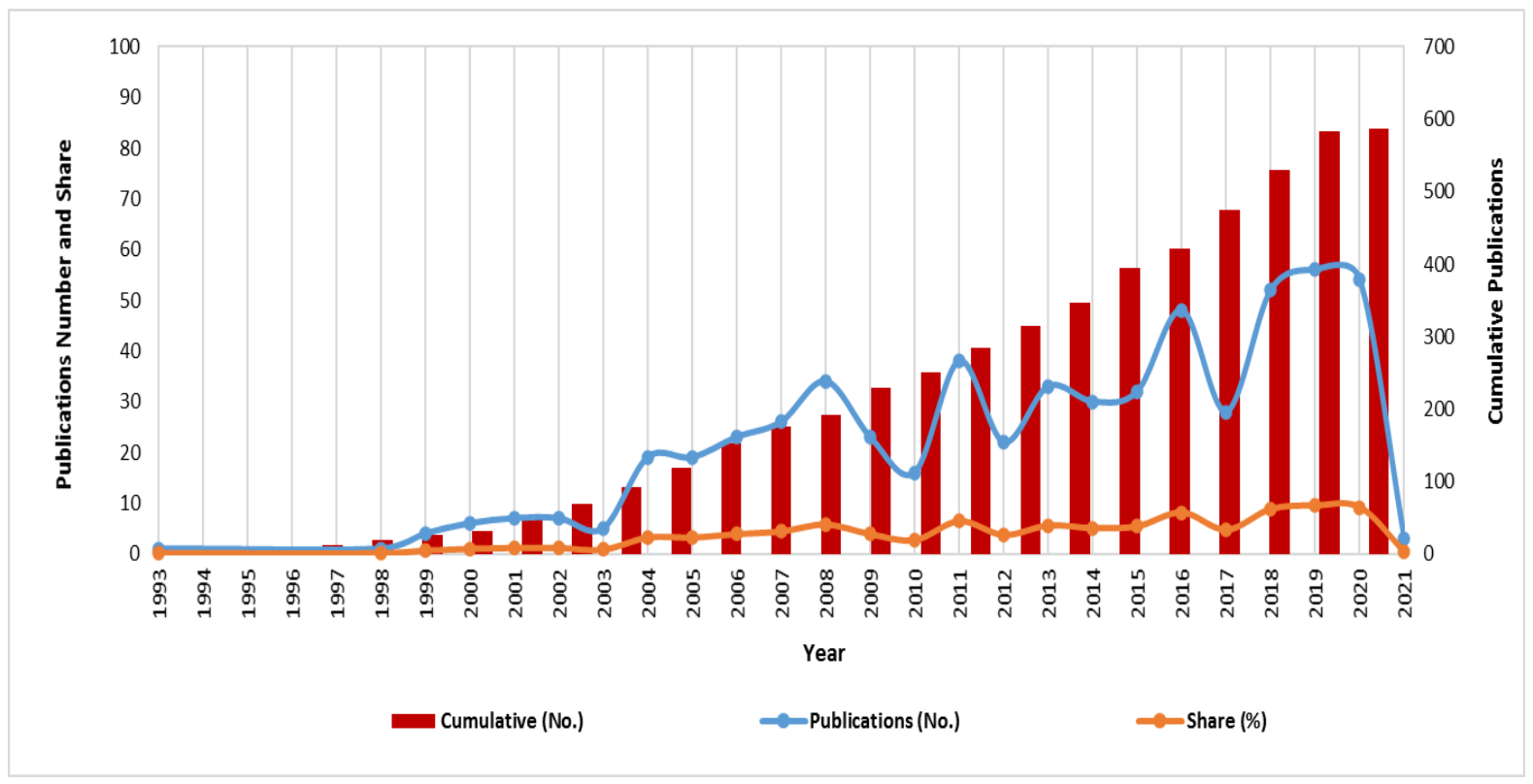

Figure 2: Annual growth in publications on perceptions, attitudes, preferences and consumer behaviour on GM food (1981-present day)

\subsection{Subjects and Category Analysis}

Two categories were used to analyse the identified articles to understand the main subjects and research themes associated with the query. The first category was using the research areas generated by the WOS database, indicating common and broad areas including engineering, agriculture and other sciences associated with the search query. The second approach used the WOS categories that described sub-fields populated from classifications of the database. Overall, 58 research areas were identified based on the first approach as well as on the top 20 research areas and their publications record were as shown in Table 1. Total related WOS categories on the basis of the second approach were 86 and the top 20 were as shown in Table

2. The top three research themes viz., Agriculture, Food Science Technology and Business Economics accounting for 62.8 per cent and categories identified viz., Food Science Technology, Agricultural Economics Policy and Economics constituting 51.2 per cent were closely related. 
Table 1: Research areas identified in the WOS and their occurrence

\begin{tabular}{|c|l|l|l|}
\hline No. & Research Areas & Record Count & Percentage \\
\hline 1. & Agriculture & 126 & 23.2 \\
\hline 2. & Food Science Technology & 123 & 22.7 \\
\hline 3. & Business Economics & 92 & 16.9 \\
\hline 4. & Environmental Sciences Ecology & 56 & 10.3 \\
\hline 5. & Nutrition Dietetics & 56 & 10.3 \\
\hline 6. & Communication & 48 & 8.8 \\
\hline 7. & Social Sciences other Topics & 47 & 8.7 \\
\hline 8. & Public Environmental Occupational Health & 42 & 7.7 \\
\hline 9. & Science Technology other Topics & 41 & 7.6 \\
\hline 10. & History Philosophy of Science & 39 & 7.2 \\
\hline 11. & Biotechnology Applied Microbiology & 37 & 6.8 \\
\hline 12. & Behavioural Sciences & 25 & 4.6 \\
\hline 13. & Mathematics & 23 & 4.2 \\
\hline 14. & Mathematical Methods in Social Sciences & 22 & 4.1 \\
\hline 15. & Psychology & 16 & 2.9 \\
\hline 16. & Engineering & 15 & 2.8 \\
\hline 17. & Biomedical Social Sciences & 13 & 2.4 \\
\hline 18. & Education Educational Research & 11 & 2.0 \\
\hline 19. & Biochemistry Molecular Biology & 10 & 1.8 \\
\hline 20. & Philosophy & 9 & 1.7 \\
\hline & & & \\
\hline
\end{tabular}

Table 2: Identified WOS categories and their occurrence

\begin{tabular}{|l|l|l|l|}
\hline No. & Web of Science Categories & Record Count & Percentage \\
\hline 1. & Food Science Technology & 123 & 22.7 \\
\hline 2. & Agricultural Economics Policy & 88 & 16.2 \\
\hline 3. & Economics & 67 & 12.3 \\
\hline 4. & Nutrition Dietetics & 56 & 10.3 \\
\hline 5. & Communication & 48 & 8.8 \\
\hline 6. & Public Environmental Occupational Health & 42 & 7.7 \\
\hline 7. & History Philosophy of Science & 39 & 7.2 \\
\hline 8. & Environmental Sciences & 38 & 7.0 \\
\hline 9. & Biotechnology Applied Microbiology & 37 & 6.8 \\
\hline 10. & Environmental Studies & 29 & 5.3 \\
\hline 11. & Social Sciences Interdisciplinary & 28 & 5.2 \\
\hline 12. & Agriculture Multidisciplinary & 26 & 4.8 \\
\hline 13. & Behavioural Sciences & 25 & 4.6 \\
\hline 14. & Multidisciplinary Sciences & 24 & 4.4 \\
\hline 15. & Business & 23 & 4.4 \\
\hline 16. & Mathematics Interdisciplinary Applications & 22 & 4.1 \\
\hline 17. & Social Sciences Mathematical Methods & 22 & 4.1 \\
\hline 18. & Ethics & 17 & 3.1 \\
\hline 19. & Green Sustainable Science Technology & 15 & 2.8 \\
\hline 20. & Social Sciences Biomedical & 13 & 2.4 \\
\hline
\end{tabular}




\subsection{Keywords Analysis}

The analysis of keywords is essential for detailing the themes of a given subject and identifying its research hotspots compared to other disciplines. According to Torres et al. (2020), keyword analysis enables researchers to explore and focus on dominant research subjects and themes. Using the VOSviewer software, 2,150 words were identified from the downloaded documents and on using a threshold of five (i.e., at least five times the keywords get repeated across the searched articles), 178 keywords met the criterion. A bibliographic coupling of the resultant keywords is shown in Figure 3.

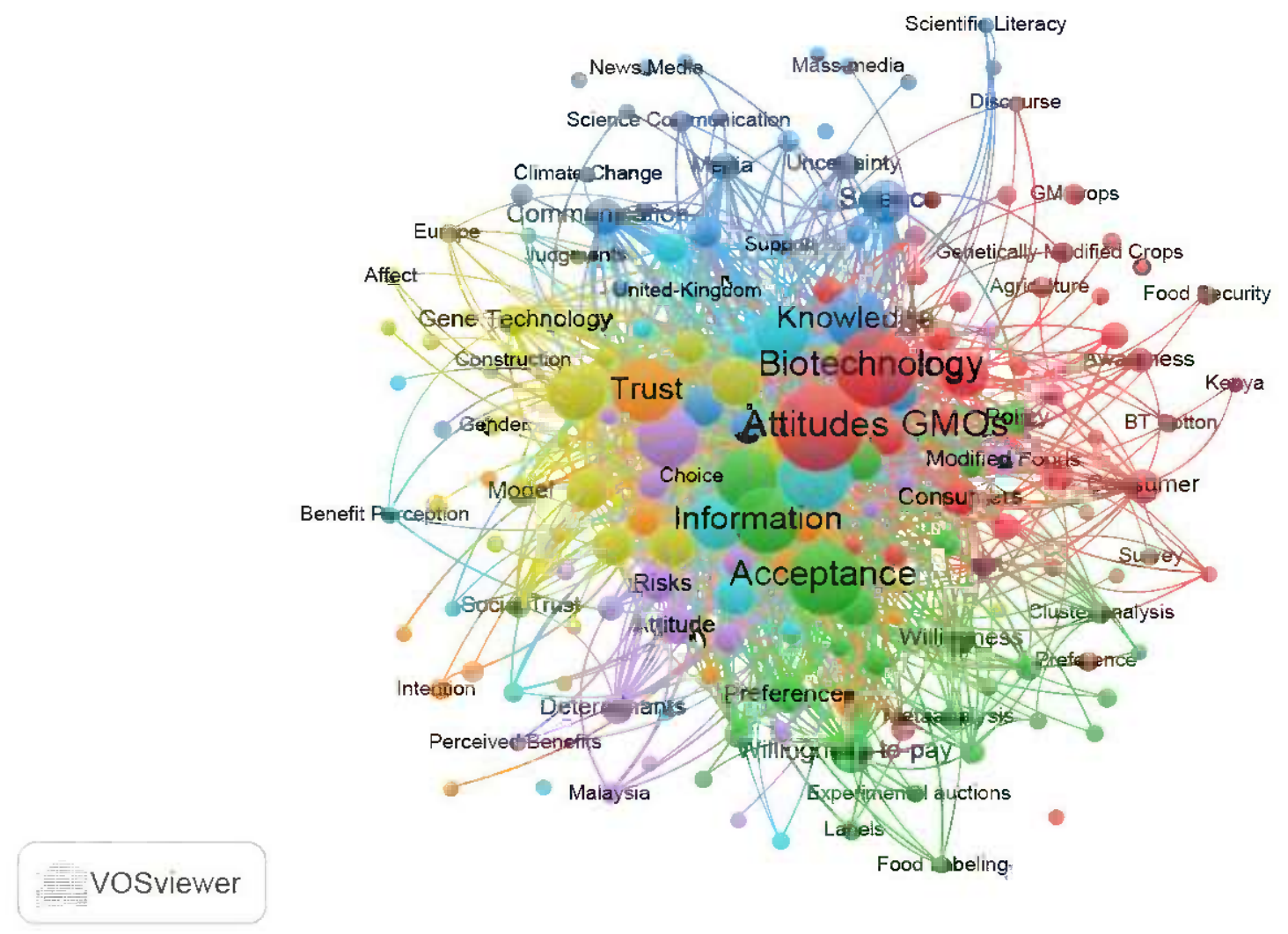

Figure 3: Bibliographic coupling of keywords

Keywords with stronger links to each other included attitude, acceptance, biotechnology, perceptions, information, genetically modified foods, knowledge and benefits evident from the size of their circles. The observations corresponded to their frequency at 167, 118, 138, 110, 99, 90, 81, 86 and 69 times in respective order. The colours of the various keywords corresponded to their research themes and categories as classified by the WOS. 


\subsection{Geographical Distribution of Retrieved Documents}

The most active publishers on the subject of GM food perceptions, attitudes, preferences and consumer behaviour were the authors from European countries $(n=320)$ and United States $(n=161)$ followed by the African $(n=20)$ and Asian regions $(n=133)$ which contributed the least to the available literature. The top 15 publishing countries and their gross domestic product (GDP) per capita is presented in Table 3. The involvement in GMO research was favoured in developed and fast developing countries with high per capita GDP.

Table 3: Top 15 countries involved in publications on GM food perceptions, attitudes, preferences and consumer behaviour

\begin{tabular}{|lll|}
\hline Country & Frequency $(\boldsymbol{\%}) \mathbf{N}=\mathbf{5 4 3}$ & GDP per capita $(\mathbf{\$})$ \\
\hline USA & $138(25.4)$ & 62,530 \\
\hline England & $55(10.1)$ & 46,659 \\
\hline Peoples Republic of China & $54(9.9)$ & 16,117 \\
\hline Australia & $32(5.9)$ & 49,854 \\
\hline Netherlands & $32(5.9)$ & 56,935 \\
\hline Canada & $31(5.7)$ & 49,031 \\
\hline Germany & $29(5.3)$ & 53,919 \\
\hline Italy & $23(4.2)$ & 42,492 \\
\hline Spain & $22(4.1)$ & 40,903 \\
\hline Malaysia & $21(3.9)$ & 28,364 \\
\hline Denmark & $19(3.5)$ & 57,804 \\
\hline Belgium & $18(3.3)$ & 51,934 \\
\hline Switzerland & $18(3.3)$ & 68,628 \\
\hline France & $16(2.9)$ & 46,184 \\
\hline Turkey & $15(2.8)$ & 28,424 \\
\hline
\end{tabular}

\subsection{Active Countries}

The USA, England, China, Australia, Netherlands and Canada were some of the top publishers as shown in Table 3. The bibliographic coupling using the VOSviewer also interrelated these countries as shown in Figure 4 based on occurrence of articles and citations. Sixty-seven countries were identified and by setting a threshold of 2 documents per country, 49 were included in the bibliographic coupling. Countries with the strongest linkages included USA, China, England, Netherlands and Spain based on their frequency of documents at 137, 54, 53, 32 and 22 times and citations of 3062, 562, 2197, 1335 and 524 times in respective order. 


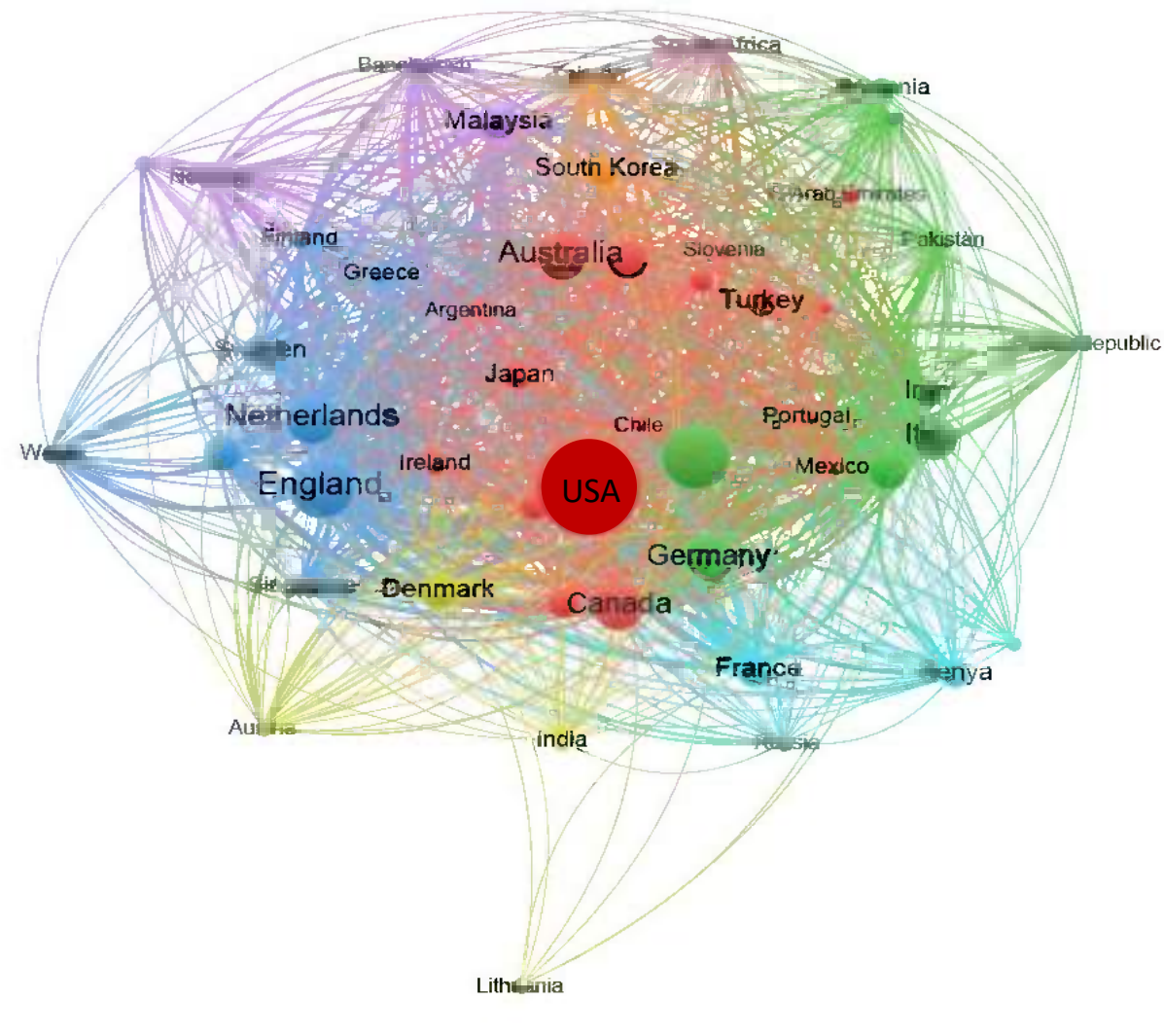

Figure 4: Bibliographic coupling of countries in research on GMO food perceptions, attitudes, preferences and consumer behaviour

\subsection{International Research Collaborations}

Countries with a minimum of 10 articles were visualized on the VOSviewer to evaluate global research collaboration in the top publishing countries as shown in Figure 5. Out of the possible 67 countries only 20 met this condition. Top five collaborators were USA, England, China, Germany and Netherlands with link strengths of 51,33, 28, 21 and 21, respectively. Most countries recorded low link strength of $<10$, which was indicative of limited international research collaboration. 


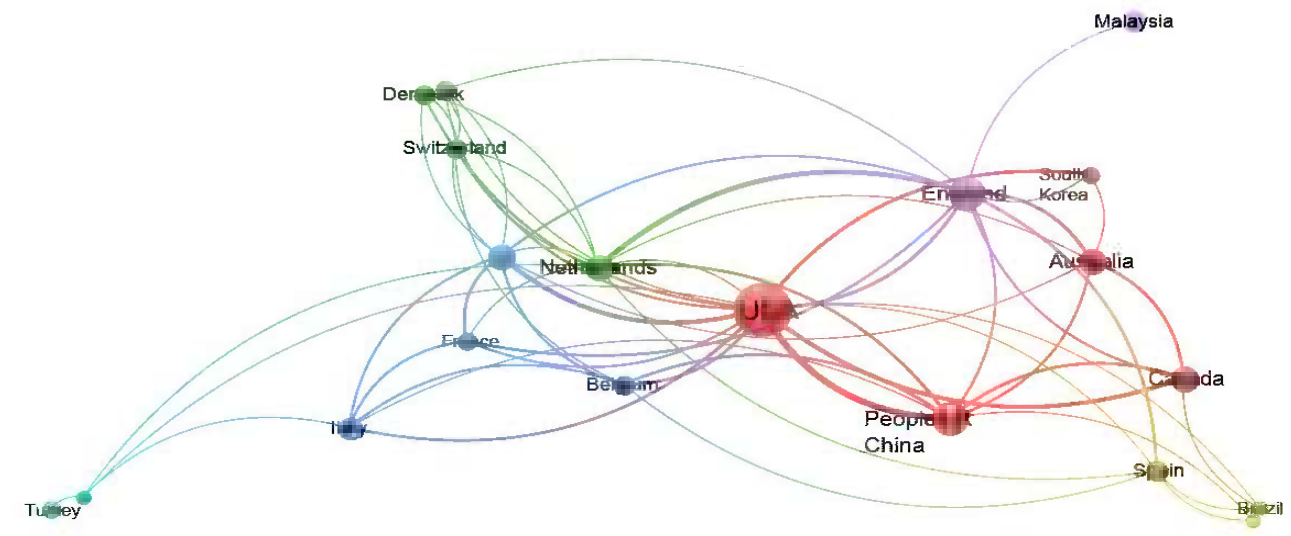

Vosviewer

Figure 5: A network visualization map of research collaborations among countries with a minimum research output of 10 articles on GMO food perceptions, attitudes, preferences and consumer behaviour

\subsection{Citation Analysis}

The 543 identified articles received 11,306 citations with an average of 20.8 per article and a total h-index of 52. The sum of citing articles was 7,333 and 6,930 excluding self-citations. When a threshold of five documents for each country was used, 28 met the requirement and the USA, England, China, Spain and Netherlands with 3062, 2197, 562, 524 and 1335 recorded top citations and a link strength of $824,692,508,383$ and 354 respectively. The network visualization of the co-citations using the VOS viewer software was as given in Figure 6.

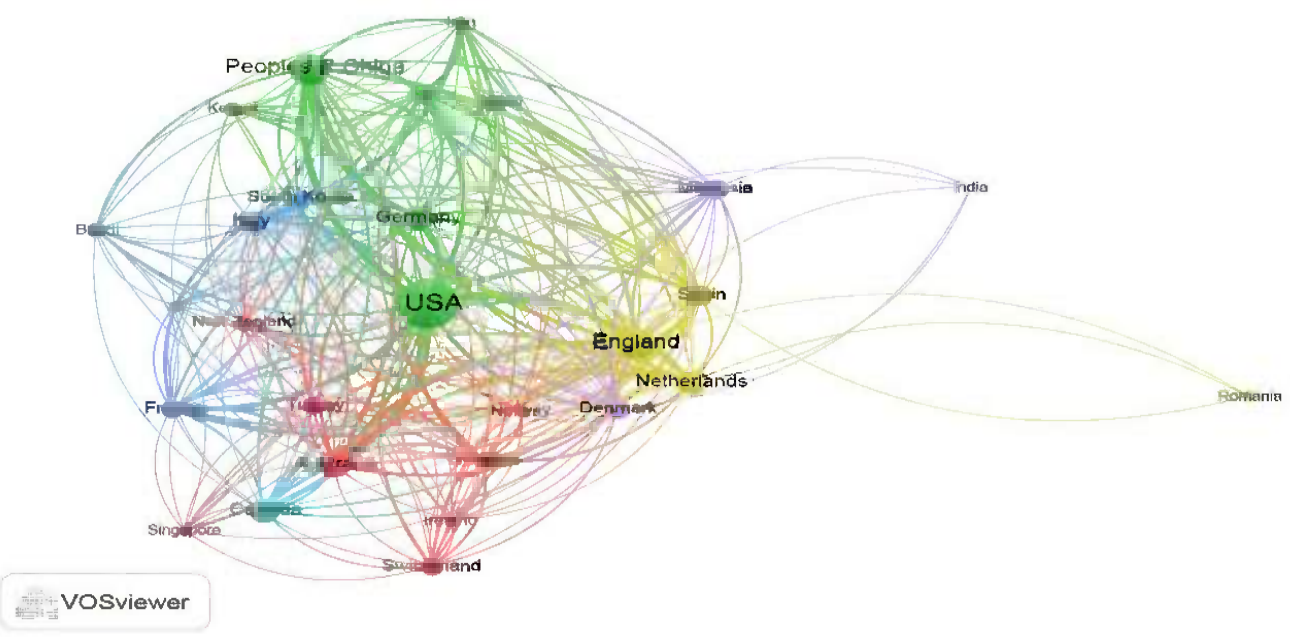

Figure 6: A network visualization map on the effect of publications from countries with a minimum of five articles. 


\subsection{Active Institutions}

Six hundred and forty-five institutions were involved in publishing research of GMO food perceptions, attitudes, preferences and consumer behaviour, and the top 10 publishing institutions are shown in Table 4 with Europe and USA having seven of them. The National University of Malaysia topped with $19(3.5 \%)$ publications while Wageningen University Research and Ghent University followed with 16 and 14 publications, respectively (Table 4).

Table 4: Top publishing institutions on GMO consumption, perceptions and attitudes

\begin{tabular}{|lll|}
\hline Institution & Record Count & Percentage \\
\hline The National University of Malaysia & 19 & 3.5 \\
\hline Wageningen University Research & 16 & 2.9 \\
\hline Ghent University & 14 & 2.6 \\
\hline ETH Zurich & 12 & 2.2 \\
\hline Chinese Academy of Sciences & 11 & 2.0 \\
\hline Rutgers State University New Brunswick & 11 & 2.0 \\
\hline University of North Carolina & 11 & 2.0 \\
\hline AARHUS University & 10 & 1.8 \\
\hline Michigan State University & 10 & 1.8 \\
\hline CGIAR & 9 & 1.7 \\
\hline
\end{tabular}

The bibliographic coupling of the various institutions using the VOSviewer is shown in Figure

7. The minimum thresholds of 5 articles and 15 citations per organization were met by 26 institutions. The National University of Malaysia, Newcastle University, University of Ghent, Wageningen University Research and University of Alberta exhibited the highest interrelation with a total link strength of 2714, 2425, 2403, 1960 and 1294, respectively.

\subsection{Active Journals}

Top 10 active journals in publishing the research query related areas were as shown in Table 5. The most prolific journals were the 'British Food Journal', 'Food Quality and Preference' and 'Appetite' with $5.5 \%, 4.6 \%$ and $4.25 \%$ respectively accounted for the highest total record count $(n=78)$. These top journals were drawn from the fields of food science technology and agricultural economics. Most of the journals had ranking by the Scopus at Q1 and their affiliations were mainly from the developed nations of Europe. 


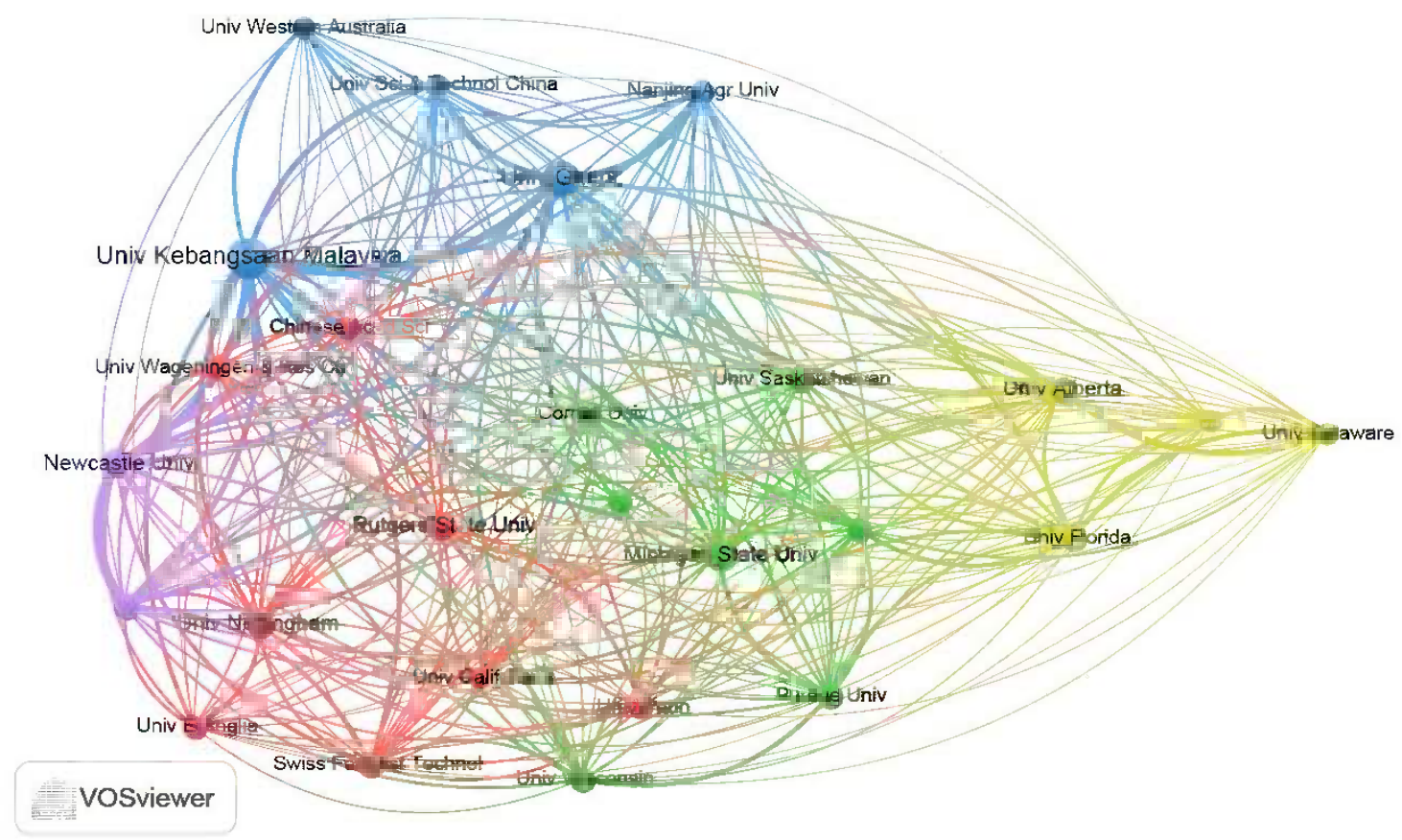

Figure 7: Bibliographic coupling of institutions involved in research on GMO food perceptions, attitudes, preferences and consumer behaviour

Table 5: Top 10 active journals in research on GMO consumption, perception and attitude

\begin{tabular}{|l|l|l|l|l|}
\hline Source & Record Count & $\begin{array}{l}\text { Percentage } \\
\text { British Food Journal }\end{array}$ & $\begin{array}{l}\text { Rank } \\
\text { Q2 }\end{array}$ & $\begin{array}{l}\text { Affiliation } \\
\text { United Kingdom }\end{array}$ \\
\hline Food Quality and Preference & 25 & 4.6 & Q1 & United Kingdom \\
\hline Appetite & 23 & 4.2 & Q1 & Netherlands \\
\hline Risk Analysis & 22 & 4.1 & Q1 & United Kingdom \\
\hline Journal of Risk Research & 31 & 3.9 & Q1 & United Kingdom \\
\hline Food Policy & 18 & 3.3 & Q1 & United Kingdom \\
\hline Public Understanding of Science & 18 & 3.3 & Q1 & United Kingdom \\
\hline African Journal of Biotechnology & 11 & 2.0 & 0 & Nigeria \\
\hline PLOS One & 11 & 2.0 & Q1 & USA \\
\hline Sustainability & 10 & 1.8 & Q2 & Switzerland \\
\hline
\end{tabular}

Out of the total 233 journals identified by the VOSviewer software, 20 met the threshold of a

minimum of five articles for every source. Their bibliographic coupling is shown in Figure 8.

Journals that had a high number of documents had bigger circles and their link strength was

higher comparatively. 


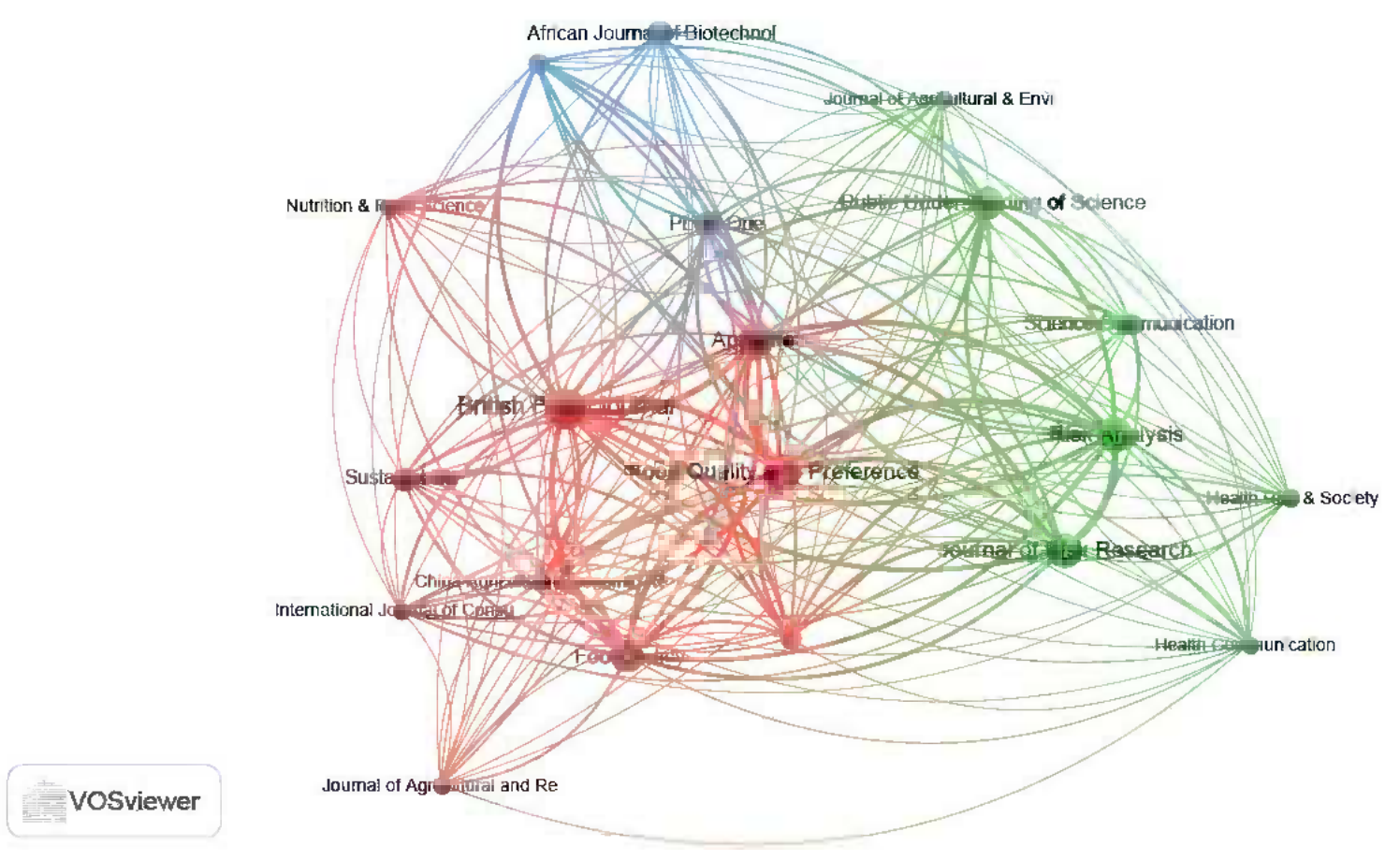

Figure 8: A network visualization on the bibliographic coupling of top sources with a minimum of five journal articles

\subsection{Funding Agencies}

Overall, 262 agencies were involved in funding the searched articles. The National Natural Science Foundation of China, The National University of Malaysia and National Science Foundation were the prominent funding agencies with a record count of $20(3.7 \%), 16(2.9 \%)$ and $9(1.7 \%)$ affiliated documents, respectively. Other top funding agencies were as listed in Table 6.

Table 6: Top 10 funding agencies in research on GMO consumption, perceptions and attitudes

\begin{tabular}{|l|l|l|}
\hline Funding Agencies & No. of Documents & Percentage \\
National Natural Science Foundation of China & 20 & 3.7 \\
\hline The National University of Malaysia & 16 & 2.9 \\
\hline National Science Foundation (NSF) & 9 & 1.7 \\
\hline United States Department of Agriculture (USDA) & 8 & 1.5 \\
\hline Economic Social Research Council (ESRC) & 6 & 1.1 \\
\hline European Union (EU) & 6 & 1.1 \\
\hline Genome Canada & 6 & 1.1 \\
\hline National Institute of Health (NIH)-USA & 6 & 1.1 \\
\hline United States Department of Health Human Services & 6 & 1.1 \\
\hline CGIAR & 5 & 0.9 \\
\hline
\end{tabular}




\subsection{Consumer Perception and Preference towards GM Foods}

Consumers experience anxiety towards GM food and therefore their decision on its consumption is pivotal to government and agri-business firms to prescribe policies and formulate strategies (Lucht, 2015; Engel et al., 2015). A comprehensive information on consumers' perception, preferences, attitude and response toward GM foods has been presented in the context based on the evidence from literature. A wide gap exists between acceptance for cultivation of GM crops and market across countries (Lucht, 2015). Consumers' knowledge plays a big role in influencing their attitude towards GM food purchase and consumption. For instance, a discernible attitude prevailed among the well-received consumers in the USA (without labelling) vis-à-vis EU (adopted the stringent approval and labelling) (Raybould \& Poppy, 2012). A majority of the respondents in the EU (61\% in 2010) declined to support the GM foods and surprisingly 18 per cent were not aware of the technology. The share of sample respondents not to support GM food was indeed lower (57\%) in the previous survey conducted five years before (Gaskell et al., 2011). In general, the consumers in the EU have more negative perception and less purchase intention towards GM foods in contrast to the consumer perception in North America (Moon \& Balasubramanian, 2002; Lusk et al., 2005; Lusk et al., 2006; Frewer et al., 2013). Formal education and attitude towards GM foods seem to have low correlation among consumers in the Europe (Lucht, 2015). The consumer behaviour of purchase intention banked upon the risk and benefit perceptions (Rollin et al., 2011; Hwang \& Nam, 2021) is influenced by the self-evaluation of product attributes attained through knowledge. For instance, the purchase intention increases when the GM food sold at 15 per cent discount with 'spray-free GM' label (Knight et al., 2007). Opinion is also divided on food safety between the American Association for the Advancement of Science (AAAS) researchers (88\% supported) and general public (only $37 \%$ supported) with respect to consuming GM foods (Lucht, 2015). Thus, trust is more important to convince general public. Compared to the USA 
and EU, in the rest of the world with the exception of a few, data availability is a major concern (Frewer et al., 2013). In developing nations, the positive perception towards GM foods arises owing to the persistent demand for food and nutrition (Curtis et al., 2004). Consumers in China, despite showing a positive attitude towards GM foods that have product-enhancing attributes, in the recent years have developed scepticism as more pondering discussions emerge on the consumption of GM foods (Li et al., 2002; De Steur et al., 2015). A survey of consumers $(n=2063)$ conducted in China revealed that $11.9,41.4$, and 46.7 per cent respectively reported to have a positive, neutral, or negative perception on the GM food. Around 12 per cent of the respondents claimed to be aware of the GM technology, while a majority were either 'neutral' or 'unfamiliar'. The major source of information was internet for a majority $(69.3 \%)$ and 64.3 per cent perceived that the information available on media is mostly negative towards GM food. Around 14\% even perceived GM technology is a form of bio-terrorism on the country, despite a positive attitude expressed by the China's Ministry of Agriculture and the science community (Cui \& Shoemaker, 2018). In a recent study carried out in China on analysing the perception and attitude of agri-business managers $(n=160)$ towards GM technology, it was found that they have a deep concern on GM food consumption and hence opposed the production (Deng et al., 2019). However, their attitude on GM crop farming is positively influenced by the level of expected profit and experience on GM crops research. Hwang \& Nam (2021) analysed the influence of Korean consumers $(n=1000)$ knowledge on their perception and purchase intention toward GM foods and found that the imbalance between subjective and objective knowledge influenced their decision-making process. Low level of subjective knowledge undermined the consumers' confidence on consuming GM foods. Apart from human consumption, even for livestock, from the literature evidence, the GM technologybased feed ( $B t$ corn and/or roundup ready soybean) has not created any adverse effects on animal health (De Vos \& Swanenburg, 2018). 


\section{Potential Benefits of the GMO Crops}

Literature evidence is abundant on the potential benefits of GM technology in general and specifically in the food crops (Fig. 9). Inter alia, incremental yield gain is the prime benefit and target of the technology in food crops spurred by the spill over benefit in creating resistance to various biotic and abiotic stresses. For instance, soybean has been approved for commercial cultivation with the incorporated genetic change in herbicide tolerance to Glyphosate (Roundup). Similarly, Bt corn has been developed with resistance to insect pests, especially to the European corn borer (Phillips, 2008). It has been estimated that the GMO technology has reduced the use of plant protection chemicals by 37 per cent, resulting in increased yield to the tune of 22 per cent (Klümper \& Qaim, 2014) and reduction in pesticides use by 8.2 per cent in the past two decades ${ }^{1}$, with an implicit benefit on cost reduction. Herbicide tolerant GM crops facilitate efficient weed control allowing for minimum soil tillage and erosion. In the aforementioned cases, the technology results in saving the environment being associated with reduced chemical application. Also, evidence exist on GMOs benefiting the environment reduction in $\mathrm{CO}_{2}$ emission equivalent to that of emission by 16.7 million cars in 2016 alone ${ }^{2}$. Similarly, the technology adds tolerance to abiotic stress like drought (in the case of wheat) and resistance to diseases, including late blight of potato, resulting in enhanced yield levels (Araus et al., 2019; Khan et al., 2019; Jo et al., 2014). A number of examples can be drawn on increase in the nutrition levels viz., beta-carotene rich rice (golden rice) as reviewed in Garg et al. (2018) and a unique case like enriched flavour and appearance in the case of non-browning apple (Waltz, 2015). Research also reports that the GM plants are expected to produce therapeutic recombinant protein and vaccines in the future (Phillips, 2008; Burnett \& Burnett 2019). Further, in monetary terms, the GMO technologies earn super-normal profit to the seed producing companies that own the patent.

\footnotetext{
${ }^{1}$ https://www.bio.org/blogs/gmos-have-benefits-environment

${ }^{2}$ https://www.bio.org/blogs/gmos-have-benefits-environment 


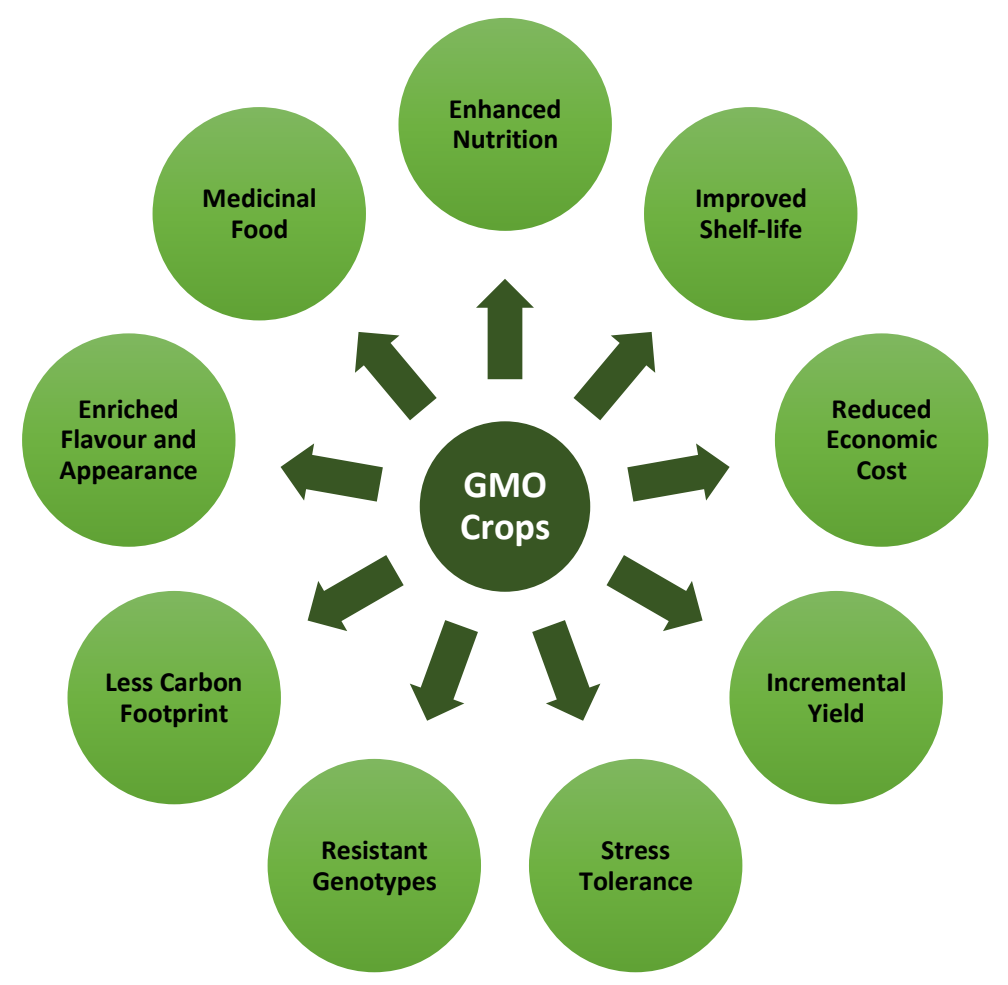

Figure 9: Potential benefits of the GMO technology in food crops

\section{Challenges and Opportunities at the Forefront}

Global food security is vital for the Sustainable Development Goals (SDG) set by the United Nations. End to hunger, better nutrition, sustainable agriculture and achieving food security are of major focus in 'SDG 2: Zero hunger'. Improved agricultural techniques and food availability also have a key role to play even in SDG 1 that focuses on poverty reduction. Genetically modified food can significantly contribute to improved food security and mitigating undernutrition. Hence, the challenges associated with regulatory and consumer acceptance of GM food should be addressed with priority and care. Possible measures must be adopted to transform the challenges into opportunities utilizing this proven tool to eradicate hunger and malnutrition.

The cultivable land is scarce, especially in highly populated developing countries and the output per hectare for small-scale farmers is comparatively low. Irrespective of farm size, GM cotton for insect resistance was widely adopted (Pray et al., 2002; Brookes \& Barfoot, 2009). 
This encourages small-scale farmers to continue to grow GMO crops which can lead to enhanced farm income in developing countries. Hence, the challenge of dwindling cultivable land can be transformed into an opportunity by reverting to adopting more GM crops. The GM food crops require lesser amounts of chemical pesticides which makes it more sustainable and environment-friendly. Wu (2006) reported a lower contamination of mycotoxins (i.e., toxic and carcinogenic chemicals produced as secondary metabolites of fungi), through pest protection, in the environment due to the adoption of GM technology. This also improves the quality of these products as the pesticide residue in the GM food products are relatively lesser. Golden Rice is a biofortified GM product with high beta-carotene. Similarly, GM foods have higher content of micronutrients like iron and zinc, highly beneficial especially in developing countries (Bouis, 2007; Connorton \& Balk, 2019; Díaz-Gómez et al., 2017).

GM food technology has a great possibility of developing products that possess the desired quality or nutritional value. For example, tomatoes with extended shelf-life and improved flavor and oilseed plants containing improved fatty acid profiles, attract consumers (Lassoued et al., 2021). But the substantial equivalence of the modified food product to conventionally developed products is important. The trait that is incorporated in the GM food product may lead to unintended side-effects which need to be assessed. For instance, GM foods with newly introduced proteins have reported potential allergenicity (Kuiper et al., 2001). Extensive research is yet to be carried out to produce a modified food product with superior properties and substantial equivalence but no significant side-effects. Emergence of efficient and accurate editing tools such as clustered regularly interspersed short palindromic repeats - associated proteins (CRISPR-Cas) has opened pathways to address the concerns of foreign gene introduction and off-target effects and commercialization of derived products (Chen et al., 2019; Gao, 2021). 
The labelling of products from GMO, particularly in Europe, have made these products stand out of the alternatives, raising the suspicion of the consumers and at the same time increased the cost involved. The separation of GM food products from non-GM food products was made mandatory in all stages of the production - from 'field to fork' (Azadi et al., 2016). In developing countries, this created an additional pressure as the labeling capacities are still in the nascent stage. Hence, many developing countries like Indonesia and India have to either remain GM-free or just continue with commercial GM crop production (like $B t$ cotton) instead of GM food crops (Paarlberg, 2002; https://www.isaaa.org/resources).

On the other hand, the consumer attitude towards genetically modified food products is still largely negative, particularly in EU and developing countries (Curtis et al., 2004; Turnbull, 2021; Entine et al., 2021). Lack of consistent regulatory policies and approvals in spite of evidence about safety of GMO foods and sensational media reports strengthen consumer scepticism. Various issues like allergenicity, destruction of agricultural diversity, resistance to antibiotics, health risks are reported to be among the potential health and safety challenges (Gaskell et al., 1999; Haslberger, 2000; Lassoued et al., 2021). The gene flow through pollen leading to fertilization in other species is another concern raised. There is a lack of awareness among consumers and producers on GM food products. The commercialization and availability of GM foods is sub-optimal due to higher cost ( $\$ 24.5$ million for GM regulatory pipeline vs \$10.5 million as conventional crop, Lassoued et al., 2021), lack of harmonized global regulation and mis- information by environmental interest groups (Virgin et al., 2007; Entine et al., 2021). Collaborative initiatives by research labs with commercial firms is essential to develop GM food products. Awareness has to be spread among consumers regarding GM foods with science-based evidence to promote the products. Further, governments should formulate and implement necessary policies and assure the public regarding the safety aspects besides facilitating promotion of beneficial GM food products relevant for solving the hunger and nutrition issues. 


\section{DISCUSSION}

The current study is aimed at assessing the literature on consumer perceptions, attitudes, preferences and response toward GM foods. The preference and consumption to foods whose genetic composition has been modified by transformation remains controversial globally (Deng et al., 2019). Proponents of GM foods argue that it has positive impacts in addressing the global food insecurity amidst the climate change era and consequent economic growth (Singhal, 2018). Conversely, the opponents believe it will alter the characteristics of native food (taste, appearance and texture), result in allergic reactions, cause harmful health effects and in the long-term, lead to environmental degradation (Zhang et al., 2016). From these viewpoints, the debate on the benefits, risks, perceptions, attitudes and consumer preferences on GMO foods are widely documented (Cui \& Shoemaker, 2018; Raman, 2018; Hwang \& Nam, 2021).

An inventory on consumers' decision on GM food becomes mandatory to formulate policies and strategies (Lucht, 2015; Engel et al., 2015). Literature evidence alarms that the consumer response towards GM foods is largely negative, though the trend is changing in the recent past, especially post-implementation of stringent rules likes labelling. A majority of such studies have been carried out in the capitalist countries exhibiting a positive response, whereas, in the developing world, the literature is scanty and show a negative response towards the GM foods (Frewer et al., 2013). Consumers positive response is largely influenced by the decision of the governments whether to ban or approve the GM crops cultivation (Gaskell et al., 2010). Similarly, the public support increases when the potential benefits of the GM technology are well articulated (Desaint \& Varbanova, 2013), consumption increases with a price discount (Knight et al., 2007), when people trust the government, believe science with a positive influence by the media (Curtis et al., 2004). For instance, labelling as 'spay-free GM' fruits followed by 15 per cent price discount in comparison to 'organic' fruits, the sales have increased from an experimental study reported by Knight et al. (2007). Singhal (2018) listed 
that the consumption of GM foods is influenced by factors like the acceptance rate of the product, prevailing information, higher level of income and ethical consumption. In the recent years/studies, it is being articulated that the specialised researchers like biotechnologists with economics interest supports the technology by citing its potential benefits (Deng et al., 2019). The negative response, however, is largely attributed to the social stigma among consumers in buying the GM foods (Mather et al., 2012), media information (Cui \& Shoemaker, 2018), stringent regulations in production and trade (Paarlberg, 2002), neophobia and psychological fear of health risk posed by innovative technologies and food products (Siegrist, 2008). Surprisingly, high educated people with more income earning capacity along with higher level of food involvement as well as greater exposure to negative information tend to overestimate their actual knowledge level leading to a higher/lower level of risk/benefit perception, and lower intention towards the purchase of GM foods (Hwang and Nam, 2021).

Literature on GMO food perceptions, attitudes, preferences and consumer behaviour is on a growing trend associated with recognition by international organizations and scientists as a viable, sustainable and safe solution to the global food insecurity indispensable in the era of climate change (Dong et al., 2019). The retrieved documents in this study were not only limited to food science technology, nutrition and dietetics but also span over other disciplines including agricultural economics, environmental sciences and applied genomics and microbiology to cite a few. A related scientometric analysis on GMO related research since 1995 to 2014 also concluded that the subject was multidisciplinary after identifying 117 subject categories affiliated to the search (Zhang et al., 2016).

The current study indicated that the USA, England and China are the leaders in publications on the searched query. China is one of the countries where food insecurity is on the rise due to a growing population with improved purchasing power by their largest segment of middleclass and demand for biofuels and feed (Mukhopadhyay et al., 2018). It is one of the leading 
countries to adopt GM technology for crop production and protection (Deng et al., 2019). A research by Wong and Chan (2016) also noted that the USA, China and European countries were the hotspots for GMO application in agriculture. The inclusion of the USA, England and other European countries among the top publishers in the research is not a surprise given their research infrastructure with access to advanced technologies, abundant research funding and highly trained human resource vis-à-vis developing countries of Asia (with the exception of China) and Africa. Zhong et al. (2016) reported a similar trend in a bibliometric analysis on natural resource accounting, which established that developed countries and fast-growing developing countries such as India and China had high numbers of published articles.

In the current study, two major research areas/ categories were evident in the analysed literature: food science technology and agricultural economics. The former is a multidisciplinary field applying principles of analytical chemistry, quality control, food management and safety, engineering and biotechnology, all relevant to the searched query. Agricultural economics deals with optimizing crop and food production and distribution and concurrently enhancing safety to alleviate any consumer concerns in the processes. It is in the field of agricultural economics that the preferences, perceptions and consumer behaviour towards GMO foods can be derived.

In this research, lead journals publishing impact of GM foods were from the food science technology, biotechnology and economics disciplines, mainly affiliated to the developed countries of Europe and the USA. This observation alludes to the fact that funding and investment on research and development is a determining factor of research output and improved scientific performance as highlighted by Ebadi and Schiffauerova (2015). The suggestion also explains the limited research output from low-income developing countries whose investment on research and development is limited (Chadha et al., 2013; UIS, 2019). In the present study, h-index and citations were indicative of wide readership in the searched 
subject. This trend could be associated with the optimism about GMO foods as their capacity to deliver towards future food security, and thus sustainable economies as projected by Gatew and Mengistu (2019). Similarly, high readership on the searched GMO food aspects could be associated with the growing public awareness on the benefits and risks of consuming such foods as highlighted by Taheri et al. (2017). The high h-index associated even with low intercountry research collaboration attests to the relevance of the topic contrary to self-citations. The involvement of highly reputable journals in publishing on the topic could be associated with the high citations.

This is the first scientometric study using visualization tool on the consumer perceptions, attitudes and preferences towards GMO foods and the trends and growth on the topic since 1981 to 2021 using the WOS database. The use of the database to retrieve information on the topic excluding grey literature and non-indexed journal articles makes the conclusions drawn informative though preliminary, paving way for complex analysis. The term 'GMO food' is very general while other studies could be specific to a particular food and hence, not captured in the search. The work used the maximum known topics for the search but not all the possible ones. Despite these limitations, validation of the searched results minimized the possible errors of omission because articles could be retrieved, assessed and confirmed on their relevance with regard to the search query.

\section{CONCLUSIONS AND POLICY IMPLICATIONS}

In the attempt to capture the consumer perception and preference for GM foods through bibliometric analysis, we established the increasing trend in publication by retrieving 543 journal articles on the aforementioned topic. Thematic analysis indicated a strong interlinkage of GMO research with agriculture and food science technology. GMOs, biotechnology, attitudes and acceptance were identified as the most common keywords used in the topical research. Europe and the USA were the power houses in GM food research as captured by the 
factors like number of active institutions per research output, publication per GDP/capita and number of citations registered per article. British Food Journal, Food Quality and Preference, and Appetite have been identified as the preferred journals for the authors to publish their research output on GM food. Being a contemporary subject, a majority of the research publications were linked to the developed nations. The bibliometric analysis also indicated the escalating research outputs on GM food consumer's acceptance and preferences despite a mixed opinion among the end-users, entailing the significance of future research thrust.

\subsection{Futuristic Research on GM Foods}

With the sustained growth population, decreasing area under cultivation and the adverse effects of climate change, the need for developing crop varieties with high yield, enriched nutrition and tolerant to various biotic and abiotic stresses is becoming more important. So far this has been achieved with the help of transgenic technology. The increase in economic gain due to reduction in labour and production costs has led to the increase in the cultivation of GM crops. The adoption of GM crops globally has impacted economically and environmentally via increased crop productivity and farmers' income along with reduced cost and $\mathrm{CO}_{2}$ emission boosting stakeholders' interests and environmental health (Klumper \& Qaim, 2014; Zhang et al., 2016; ISAAA, 2018; Brookes and Barfoot, 2018).

Despite the aforementioned issues, the GM crops are released for cultivation only with regulatory approval after stringent assessments for food and feed safety. The world area under transgenic crops has increased from 1.7 million hectares in 1996 to 191.7 million hectares in 2018, registering a 113-fold increase (ISAAA, 2018). The increase in area under GM crops has led to concerns regarding the food safety, environment and socio-economic issues. There are also concerns regarding the transgene flow into non-target species leading to feralization and its negative effects on biodiversity (Mertens, 2008; Suzie et al., 2008; Lovei \& Bohn, 2010; Clark \& Maselko, 2020). Despite the environment and biosafety concerns, the genetic 
transformation technology has been a preferred choice for crop improvement and rapid development of plants with multiple favourable traits. Emergence of CRISPR-Cas9 based genome editing has provided one more cost-and time-efficient and precise tool to engineer desirable traits (Gao et al., 2021).

The studies undertaken in the past on animal health post feeding transgenic foods to rats, hens, frogs, pigs, monkeys and cows have not reported any health hazards and hence GM crops were found to be safe (Domingo, 2016; Tsatsakis et al., 2017; De Vos \& Swanenburg, 2018).

The possibility of the selectable marker genes conferring antibiotic resistance transferring to human and animal gut microbes through GM foods and resulting in the development of antibiotic resistance was also raised as a concern (Netherwood et al., 2004; Heritage, 2004; Keese, 2008). Efforts on having marker-free integration events to overcome this concern (Tuteja et al., 2012; He \& Zhao, 2020) and genome editing of native in-lieu of introducing foreign DNA (Mackelprag \& Lemaux, 2020), were also successful.

The possible introgression of the transgenes from transgenic crops to wild relatives is a potential risk for loss of biodiversity and the gene flow to weedy relatives will lead to emergence of herbicide-resistant 'superweeds'. The pollen-mediated transfer of transgene from GM crops to traditional cultivars and to their wild relatives reported in maize, rice, cotton, barley, beans, creeping bent grass and rapeseed, is a major adverse effect on the environment (Watrud et al., 2004; Chen et al., 2004; Ford et al., 2006; Han et al., 2015; Yan et al., 2015).

Extensive cultivation of insect resistant crops and the high selection pressure may lead to resistance in the targeted insect population causing emergence of new insect biotypes (Bawa \& Anilakumar, 2013; Gilbert, 2013). The strategies involving the pyramiding of multiple insect-resistant genes and inclusion of susceptible host in cultivation as a refuge crop have been utilized successfully to delay the breakdown of resistance. 
The major limiting factors associated with the development and cultivation of transgenic crops are the high cost of safety assessment including containment facilities and the lengthy and complex regulatory approval process required before the commercial release (Davison, 2010; Miller \& Bradford, 2010). Regulatory approval post safety evaluations is the longest phase in the transgenic product development and commercialization (McDougall, 2011) and the estimated time is around five and seven years in European Union and the United States respectively (Smart et al., 2017).

Adoption of transgenic technologies has led to social and ethical concerns viz., restricted access to genetic resources, loss of traditional farming practices and monopoly by tech corporates and the consequent competitive disadvantage posing loss of income and livelihood for resourcepoor farmers. The scientific evidence on the environmental and health impacts of GMOs is still emerging and there is no conclusive evidence on the negative impacts. Though the perceptions of the public about GMOs in agriculture and food is divided in across developing and developed economies with an overall inclination towards avoiding GM food and products, the scenario is witnessing a discernible change. Governments all over the world are implementing various regulatory guidelines and policies to ensure safety of the consumers, producers, farm animals and the environment. The policy differences among countries have profound cross border influence in global trade in a world with free market. Further, the influence of various stakeholders and the overall techno-economic situation of the country also impact the functioning of the regulatory bodies and their decisions. Transparency, clarity, competency, impartiality, timely decisions, science-based assessment, effective monitoring, national and international priorities, trade orientation, single window approach, cost-effectiveness, coordination among the stakeholders and public participation in the process are some of the desirable attributes for an ideal regulatory framework. 
Regarding the international agreements, the 'Cartagena Protocol' on Biosafety came into force in September 2003, and by June 2020 has been ratified by 173 countries. The objective of the Protocol is to "contribute to ensuring an adequate level of protection in the field of the safe transfer, handling and use of living modified organisms resulting from modern biotechnology that may have adverse effects on the conservation and sustainable use of biological diversity, taking also into account risks to human health, and specifically focusing on transboundary movements". Besides, the Protocol aims to protect biological diversity from the potential risks posed by the GMOs. It establishes an advance informed agreement (AIA) procedure so that, countries are provided with the necessary information to make informed decisions before agreeing to the import of such organisms into their territory (Cartagena Protocol on Biosafety, 2021).

Public acceptance and proper policies are keys for agricultural, environmental and socioeconomic benefits of transgenic crops to reach the poor and the needy. More important is the regional level regulatory harmonizations that facilitate data transportability for expediting the decision-making with regard to bio-safety. The benefits of the transgenic crops in the present scenario as well as in future depends upon science-based forward-looking regulatory steps,

critically looking at the benefits rather than the risks, agricultural productivity with due considerations to environmental conservation and sustainability, and most importantly taking into consideration the millions of hungry and impoverished population (ISAAA, 2018).

\subsection{Policy Implications}

In the light of the aforementioned review and discussion, we draw a raft of policy prescriptions for research, industries and society for a focused and pragmatic approach in GM food crops.

\subsubsection{Research}

- Local governments enabling favourable environment for R\&D and outreach addressing the socio-political concerns and debates around GM foods/including gene edited crops. 
- Invest and harness the potential of GM techniques including gene editing in crops for clean fuel production and biodegradation to combat the adverse climate change.

- Stringent, harmonised and universal protocols for testing the GM food based recombinant vaccines for public use.

- Harmonizing regulatory framework across the world in lieu of the current processbased regulation in EU countries and product-based regulation in North America, Argentina and Brazil.

- Bridging the gap between researchers' and public opinion on GM food and safety through evidence-based studies.

\subsubsection{Agri-Food Industries}

- Promoting public awareness on compliance of food safety standards and product labelling.

- Agri-food companies owning GMOs should disclose the critical technical details in the public domain allaying the apprehensions about their safety.

- GMO based food manufacturing companies have to warrant a safer and healthier food.

- Enabling the 'traceability' feature using the blockchain technology.

\subsubsection{Society}

- Informed decision-making process in terms of scientific production as well as consumption.

- Belief and acceptance of evidence-based science than opinion-based misperceptions.

- Creating awareness on food safety protocols and food labelling.

Clearly, realisation of GM technology in the agricultural food system needs due diligence and in-depth analysis on associated risks and/or benefits to multiple stakeholders on a case-to-case basis before commercialisation. 


\section{REFERENCES}

Araus, J. L., Serret, M. D. \& Lopes, M. S. 2019. Transgenic solutions to increase yield and stability in wheat: shining hope or flash in the pan? Journal of Experimental Botany, 70(5), 1419-1424. https://doi.org/10.1093/jxb/erz077

Azadi, H., Samiee, A., Mahmoudi, H., Jouzi, Z., Rafiaani Khachak, P., De Maeyer, P., \& Witlox, F. (2016). Genetically modified crops and small-scale farmers: main opportunities and challenges. Critical reviews in biotechnology, 36(3), 434-446. https://doi.org/10.3109/07388551.2014.990413

Bawa, A.S., \& Anilakumar, K.R. (2013). Genetically modified foods: safety, risks and public concerns-a review. Journal of Food Science Technology, 50(6), 1035-1046. https://dx.doi.org/10.1007/s13197-012-0899-1

Bouis, H.E. (2007). The potential of genetically modified food crops to improve human nutrition in developing countries. Journal of Development Studies, 43(1), 79-96. https://doi.org/10.1080/00220380601055585

Brookes, G., \& Barfoot, P. (2018). Farm income and production impacts of using GM crop technology 1996-2016. GM Crops Food, 9(2), 59-89. https://doi.org/10.1080/21645698.2018.1464866

Brookes, G., \& Barfoot, P. (2009). GM crops: global socio-economic and environmental impacts 1996-2007. UK: PG Economics Ltd.

Burnett, M.J.B., \& Burnett, A. C. (2019). Therapeutic recombinant protein production in plants: Challenges and opportunities. Plants, People, Planet, 2(2), 121-132. https://doi.org/10.1002/ppp3.10073

Chadegani, A., Salehi, H., Yunus, M., Farhadi, H., Fooladi, M., Farhadi, M., \& Ebrahim, N. (2013). A comparison between two main academic literature collections: Web of Science and Scopus databases. Asian Social Science, 9(5), 18-26. https://doi.org/10.5539/ass.v9n5p18

Chadha, G.K., Ramasundaram, P., \& Sendhil, R. (2013). Is Third World agricultural R\&D slipping into a technological orphanage. Current Science, 105 (7), 908-913. Retrieved June 5, 2021, from http://www.jstor.org/stable/24098510

Chen, K., Wang, Y., Zhang, R., Zhang, H., \& Gao, C. (2019). CRISPR/Cas Genome Editing and Precision Plant Breeding in Agriculture. Annual Review of Plant Biology, 70, 667697. https://doi.org/10.1146/annurev-arplant-050718-100049

Chen, L.J., Lee, D.S., Song, Z.P., Suh, H.S., \& Lu, B. (2004). Gene flow from cultivated rice (Oryza sativa) to its weedy and wild relatives. Annals of Botany, 93(1), 67-73. https://dx.doi.org/10.1093/aob/mch006

Clark, M., \& Maselko, M. (2020). Transgene biocontainment strategies for molecular farming. Frontiers in Plant Science, 11, 210, https://doi.org/10.3389/fpls.2020.00210 
Connorton, J.M., \& Balk, J. (2019). Iron biofortification of staple crops: Lessons and challenges in plant genetics. Plant and Cell Physiology, 60(7), 1447-1456. https://doi.org/10.1093/pcp/pcz079

Cui, K. \& Shoemaker, S. (2018). Public perceptions of genetically modified (GM) food: A nationwide Chinese consumer study. NPJ Science of Food, 2 (10), 1-8. https://doi.org/10.1038/s41538-018-0018-4

Curtis, K.R., McCluskey, J.J., \& Wahl, T.I. (2004). Consumer acceptance of genetically modified food products in the developing world. AgBioForum, 7(1\&2), 69-74. https://digitalcommons.usu.edu/appecon_facpub/115/

Davison, J. (2010). GM plants: Science, politics and EC regulations. Plant Science, 178(2), 94-98. https://doi.org/10.1016/j.plantsci.2009.12.005

De Steur, H., Liqun, G., Straeten, D.V.D., Lambert, W., \& Gellynck, X. (2015). The potential market for GM rice with health benefits in a Chinese high-risk region. Journal of Food Products Marketing, 21(3), 231-243. https://doi.org/10.1080/10454446.2013.855993

De Vos, C.J., \& Swanenburg, M. (2018). Health effects of feeding genetically modified (GM) crops to livestock animals: A review. Food and Chemical Toxicology, 117, 3-12. https://doi.org/10.1016/j.fct.2017.08.031

Deng, H., Hu, R., Pray, C. \& Jin, Y. (2019). Perception and attitude towards GM technology among agribusiness managers in China as producers and as consumers. Sustainability, 11(5), 1342. https://doi.org/10.3390/su11051342

Desaint, N., \& Varbanova, M. (2013). The use and value of polling to determine public opinion on GMOs in Europe: limitations and ways forward. GM Crops \& Food, 4(3), 183-194. https://doi.org/10.4161/gmcr.26776

Díaz-Gómez J, Twyman R.M., Zhu, C., Farre. G., Serrano, J.C.E., Portero-Otin, M., Muñoz, P., Sandmann, G., Capell, T., Christou, P. (2017). Biofortification of crops with nutrients: factors affecting utilization and storage. Current Opinion in Biotechnology, 44, 115-123. https://doi.org/10.1016/j.copbio.2016.12.002

Domingo, J.L. (2016). Safety assessment of GM plants: an updated review of the scientific literature. Food and Chem Toxicology, 95, 12-18. https://doi.org/10.1016/j.fct.2016.06.013

Dong, W., Anwar, M., Nawaz, M., Rongting, Z., Asmi, F., Sajjad, A. \& Hammad, A. (2019). Knowledge mapping of GMO/GMF research in social sphere. Cogent Food and Agriculture, 5(1), 1602103. https://doi.org/10.1080/23311932.2019.1602103

Ebadi, A., \& Schiffauerova, A. (2015). How to receive more funding for your research? Get connected to the right people!. PLoS ONE, 10(7), e0133061. https://doi.org/10.1371/journal.pone.0133061

Engel, K., Schauzu, M., Klein, G., \& Somogyi, A. (1995). Regulatory oversight and safety assessment of genetically modified foods in the European Union. In Genetically Modified Foods: Safety Aspects; Engel, K.H., Takeoka, G.R., Teranishi, R., Eds.; ACS: Washington, DC, USA. 
Entine, J., Felipe, M.S.S., Groenewald, JH. et al. (2021) Regulatory approaches for genome edited agricultural plants in select countries and jurisdictions around the world. Transgenic Research. https://doi.org/10.1007/s11248-021-00257-8

FAO (Food and Agriculture Organization) (2020). Investment costs and policy action opportunities for reaching a world without hunger (SDG 2) Rome and Bonn. https://doi.org/10.4060/cb1497en

Ford, C.S., Allainguillaume, J., Grilli-Chantler, P., Cuccato, J., Allender, C.J., \& Wilkinson, M.J. (2006). Spontaneous gene flow from rapeseed (Brassica napus) to wild Brassica oleracea. Proceedings of the Royal Society $B$ 273, 3111-3115. https://doi.org/10.1098/rspb.2006.3686

Frewer, L.J., van der Lans, I.A., Fischer, A.R.H., Reinders, M.J., Menozzi, D., Zhang, X., van den Berg, I., Zimmermann, K.L. (2013). Public perceptions of agri-food applications of genetic modification - A systematic review and meta-analysis. Trends in Food Science \& Technology, 30(2), 142-152. https://doi.org/10.1016/j.tifs.2013.01.003

Gao, C. (2021) Genome engineering for crop improvement and future agriculture. Cell, 184(6), 1621-1635. https://doi.org/10.1016/j.cell.2021.01.005

Garg, M., Sharma, N., Sharma, S., Kapoor, P., Kumar, A., Chunduri, V., \& Arora, P. (2018). Biofortified crops generated by breeding, agronomy, and transgenic approaches are improving lives of millions of people around the world. Frontiers in Nutrition, 5, 12. https://doi.org/10.3389/fnut.2018.00012

Gaskell, G., Allansdottir, A., Allum, N., Castro, P., Esmer, Y., Fischler, C., Jackson, J., Kronberger, N., Hampel, J., Mejlgaard, N., Quintanilha, A., Rammer, A., Revuelta, G., Stares, S., Torgersen, H., \& Wager, W. (2011). The 2010 Eurobarometer on the life sciences. Nature Biotechnology, 29(2), 113-114. https://doi.org/10.1038/nbt.1771

Gaskell, G., Stares, S., Allansdottir, A., Allum, N., Castro, P., Esmer, Y., Fischler, C., Jackson, J., Kronberger, N., Hampel, J., et al. (2010). Europeans and Biotechnology in 2010: Winds of Change? European Commission; Brussels, Belgium. https://repositori.upf.edu/bitstream/handle/10230/21297/europeans-biotechnology-in2010_en.pdf [Accessed on 10-06-2021]

Gaskell, G. et al. (1999) Worlds apart? The reception of genetically modified food in Europe and the U.S. Science, 285(5426), 384-387. https://doi.org/10.1126/science.285.5426.384

Gatew, H., \& Mengistu, K. (2019). Genetically modified foods (GMOs): A review of genetic engineering. Journal of Life Science and Biomedicine, 9(6), 157-163.

Gilbert, N. (2013). A hard look at GM crops. Nature, 497, 24-26. https://doi.org/10.1038/497024a

Han, S.M., Lee, B., Won, O.J., Hwang, K.S., Suh, S.J., Kim, C., \& Park, K.W. (2015). Gene flow from herbicide resistant genetically modified rice to conventional rice (Oryza sativa L.) cultivars. Journal of Ecology and Environment, 38(4), 397-403. https://doi.org/10.5141/ecoenv.2015.042 
Haslberger, A.G. (2000). Monitoring and labeling for genetically modified products. Science, 287(5452), 431-432. https://doi.org/10.1126/science.287.5452.431

He, Y., \& Zhao, Y. (2020). Technological breakthroughs in generating transgene-free and genetically stable CRISPR-edited plants. aBIOTECH, 1, 88-96. https://doi.org/10.1007/s42994-019-00013-X

Heritage, J. (2004). The fate of transgenes in the human gut. Nature Biotechnology, 22, 170172. https://doi.org/10.1038/nbt0204-170

Hwang, H. \& Nam, S. (2021). The influence of consumers' knowledge on their responses to genetically modified foods. GM Crops \& Food, 12(1), 146-157. https://doi.org/10.1080/21645698.2020.1840911

ISAAA. (2018). Global Status of Commercialized Biotech/GM Crops in 2018: Biotech Crops Continue to Help Meet the Challenges of Increased Population and Climate Change. ISAAA Brief No. 54. ISAAA: Ithaca, NY. ISAAA Briefs No. 54-2020, available at https://www.isaaa.org/resources/publications/default.asp

James, C. (2011). Global Status of Commercialized Biotech/ GM Crops, 2011. $43^{\text {rd }}$ ed. Ithaca, N.Y.: International Service for the Acquisition of Agri-biotech Applications (ISAAA); 2011.

Jo, K.R., Kim, C.J., Kim, S.J., Kim, T.Y., Bergervoet, M., Jongsma, M.A., Visser, R.G., Jacobsen, E., \& Vossen, J.H. (2014). Development of late blight resistant potatoes by cisgene stacking. BMC Biotechnology, 14, 50. https://doi.org/10.1186/1472-6750-14$\underline{50}$

Keese, P. (2008). Risks from GMOs due to horizontal gene transfer. Environmental Biosafety Research, 7(3), 123-149. https://doi.org/10.1051/ebr:2008014

Khan, S., Anwar, S., Yu, S., Sun, M., Yang, Z. \& Gao, Z.Q. (2019). Development of droughttolerant transgenic wheat: Achievements and limitations. International Journal of Molecular Sciences, 20(13), 3350. https://dx.doi.org/10.3390/ijms20133350

Klümper, W., \& Qaim, M. (2014). A meta-analysis of the impacts of genetically modified crops. PLoS ONE, 9(11), e111629. https://doi.org/10.1371/journal.pone.0111629.

Knight, J.G., Mather, D.W., Holdsworth, D.K., \& Ermen, D.F. (2007). Acceptance of GM food - an experiment in six countries. Nature Biotechnology, 25(5), 507-508. https://doi.org/10.1038/nbt0507-507

Kuiper, H.A., Kleter, G.A., Noteborn, H.P., \& Kok, E.J. (2001). Assessment of the food safety issues related to genetically modified foods. The Plant Journal, 27(6), 503-528. https://doi.org/10.1046/j.1365-313x.2001.01119.x

Lassoued, R., et al. (2021). Expert opinions on the regulation of plant genome editing. Plant Biotechnology Journal, https://doi.org/10.1111/pbi.13597

Li, Q., Curtis, K.R., McCluskey, J.J., \& Wahl, T.I. (2002). Consumer attitudes toward genetically modified foods in Beijing, China. AgBioForum, 5, 145-152. http://hdl.handle.net/10355/294 
Liao, H., Tang, M., Luo, L., Li, C., Chiclana, F., \& Zeng X-J. (2018). A bibliometric analysis and visualization of medical big data research. Sustainability, 10(1), 166. https://doi.org/10.3390/su10010166

Lovei, G.L., Bøhn, T., Hilbeck, A. (2010). Biodiversity, Ecosystem Services and Genetically Modified Organisms. Third World Network, 131 Macalister Road 10400 Penang, Malaysia. ISBN: 978-967-5412-13-4.

Lucht, J.M. (2015). Public acceptance of plant biotechnology and GM crops. Viruses, 7(8), 4254-4281. https://dx.doi.org/10.3390/v7082819

Lusk, J.L., Jamal, M., Kurlander, L., Roucan, M., \& Taulman, L. (2005). A meta-analysis of genetically modified food valuation studies. Journal of Agricultural and Resource Economics, 30(1), 28-44. http://purl.umn.edu/30782

Lusk, J.L., Bruce, T.W., House, L.O., Valli, C., Jaeger, S.R., Moore, M., \& Morrow, B. (2006). Comparative advantage in demand: Experimental evidence of preferences for genetically modified food in the United States and European Union. Journal of Agricultural Economics, 57(1), 1-21. https://dx.doi.org/10.1111/j.14779552.2006.00029.x

Mackelprag, R., \& Lemaux, P.G. (2020). Genetic engineering and editing of plants: An analysis of new and persisting questions. Annual Review of Plant Biology, 7, 659-687. https://doi.org/10.1146/annurev-arplant-081519-035916

Mather, D.W., Knight, J.G., Insch, A., Holdsworth, D.K., Ermen, D.F., \& Breitbarth, T. (2012). Social stigma and consumer benefits trade-offs in adoption of genetically modified foods. Science Communication, 34(4), 487-519. https://doi.org/10.1177/1075547011428183

McDougall, P. (2011). The cost and time involved in the discovery, development and authorisation of a new plant biotechnology derived trait. In: A consultancy study for crop life international, Pathhead, Midlothin, UK. Available at https://croplife.org/wpcontent/uploads/2014/04/Getting-a-Biotech-Crop-to-Market-PhillipsMcDougallStudy.pdf.

Mertens, M., (2008). Assessment of environmental impacts of genetically modified plants. BfN- Skripten 217. Federal Agency for Nature Conservation, New York, USA. https://www.bfn.de/fileadmin/BfN/service/Dokumente/skripten/skript217.pdf

Miller, J.K., \& Bradford, K.J. (2010). The regulatory bottleneck for biotech speciality crops. Nature Biotechnology, 28, 1012-1014. https://doi.org/10.1038/nbt1010-1012

Mongeon, P., \& Paul-Hus, A. (2015). The journal coverage of Web of Science and Scopus: a comparative analysis. Scientometrics, 106: 213-228. https://doi.org/10.1007/s11192$\underline{015-1765-5}$

Moon, W., \& Balasubramanian, S.K. (2002). Public perceptions and willingness-to-pay a premium for non-GM foods in the US and UK. AgBioForum, 4, 221-231. http://hdl.handle.net/10355/331 
Mukhopadhyay, K., Thomassin, P. \& Zhang, J. (2018). Food security in China at 2050: a global CGE exercise. Journal of Economic Structures, 7, 1-25. https://doi.org/10.1186/s40008-017-0097-4

Munro, A. (2003) Monopolization and the regulation of genetically modified crops: An economic model. Environment and Development Economics, 8(1), 167-186. https://doi.org/10.1017/S1355770X03000093

Netherwood, T., Martín-Orúe, S.M., O’Donnell, A.G., Gockling, S., Graham, J., Mathers, J.C., \& Gilbert, H.J. (2004). Assessing the survival of transgenic plant DNA in the human gastrointestinal tract. Nature Biotechnology, 22, 204-209. https://doi.org/10.1038/nbt934

Oliver, M.J. (2014) Why we need GMO crops in agriculture. Science of medicine - National Review. Missouri Medicine, 111(6), 492-507.

Paarlberg, R.L. (2002). The real threat to GM crops in poor countries: consumer and policy resistance to GM foods in rich countries. Food Policy, 27(3), 247-250. https://doi.org/10.1016/S0306-9192(02)00014-3

Phillips, T. (2008) Genetically modified organisms (GMOs): Transgenic crops and recombinant DNA technology. Nature Education, 1(1), 213.

Pray, C., Huang, J., Hu, R., \& Rozelle, S. (2002). Five years of Bt cotton in China - the benefits continue. The Plant Journal, 31, 423-30. https://doi.org/10.1046/j.1365$\underline{313 x .2002 .01401 . x}$

Raman, R. (2017). The impact of genetically modified (GM) crops in modern agriculture: A review. GM Crops \& Food, 8(4), 195-208. https://doi.org/10.1080/21645698.2017.1413522

Raybould, A., \& Poppy, G.M. (2012). Commercializing genetically modified crops under EU regulations. GM Crops \& Food, 3(1), 9-20. https://doi.org/10.4161/gmcr.18961

Rollin, F., Kennedy, J., \& Wills, J. (2011). Consumers and new food technologies. Trends in Food Science \& Technology, 22(2-3), 99-111. https://doi.org/10.1016/j.tifs.2010.09.001

Siegrist, M. (2008). Factors influencing public acceptance of innovative food technologies and products. Trends in Food Science \& Technology, 19(11), 603-608. https://doi.org/10.1016/j.tifs.2008.01.017

Shukla, M., Al-Busaidi, K.T., Trivedi, M., \& Tiwari, K.R. (2018) Status of research, regulations and challenges for genetically modified crops in India. GM Crops \& Food, 9(4), 173-188. https://doi.org/10.1080/21645698.2018.1529518

Singhal, N. (2018). A study of consumer behaviour towards genetically modified foods and the moderating effects of health consciousness. Vision: The Journal of Business Perspective, 22, 1-10. https://doi.org/10.1177/0972262918786103 
Smart, R.D., Blum, M., \& Wesseler, J. (2017). Trends in approval times for genetically engineered crops in the United States and the European Union. Journal of Agricultural Economics 68(1), 182-198. https://doi.org/10.1111/1477-9552.12171

Suzie, K., Ma, J.K.C., \& Drake, P.M.W. (2008). Genetically modified plants and human health. Journal of the Royal Society of Medicine, 101(6), 290-298. https://dx.doi.org/10.1258/jrsm.2008.070372

Sweileh, W.M., Sawalha, A.F., Al-Jabi, S.W., Zyoud, S.H., Shraim, N.Y., \& Abu-Taha, A.S. (2016). A bibliometric analysis of literature on malaria vector resistance: (1996-2015). Globalization and Health, 12(1), 76. https://dx.doi.org/10.1186/s12992-016-0214-4

Sweileh, W., \& Mansour, A. (2020). Bibliometric analysis of global research output on antimicrobial resistance in the environment (2000-2019). Global Health Research and Policy, 5(37), 1-11. https://doi.org/10.1186/s41256-020-00165-0

Szenkovics, D., Tonk, M., \& Balog, A. (2021). Can genetically modified (GM) crops act as possible alternatives to mitigate world political conflicts for food? Food and Energy Security, 10(1), e268. https://doi.org/10.1002/fes3.268

Taheri, F., Azadi, H. \& D'Haese, M. (2017). A world without hunger: organic or GM crops? Sustainability, 9(4), 580. https://doi.org/10.3390/su9040580

The Cartagena Protocol on Biosafety. (2021). https://bch.cbd.int/protocol; Accessed on 3 June 2021.

Torres, R., Carvalho, J., Cunha, M., Serrano, E., Palmeira, J. \& Fonseca, C. (2020). Temporal and geographical research trends of antimicrobial resistance in wildlife-a bibliometric analysis. One Health, 11, 100198. https://doi.org/10.1016/j.onehlt.2020.100198

Tsatsakis, A.M., Nawaz, M.A., Kouretas, D., Balias, G., Savolainen, K., Tutelyan, V,A., Golokhvast, K.S., Lee, J.D., Yang, S.H., \& Chung, G, (2017). Environmental impacts of genetically modified plants: a review. Environmental Research, 156, 818-833. https://doi.org/10.1016/j.envres.2017.03.011

Turnbull, C., Lillemo, M., \& Hvoslef-Eide, T.A.K. (2021). Global regulation of genetically modified crops amid the gene edited crop boom - a review. Frontiers in Plant Science, 24, 630396. https://doi.org/10.3389/fpls.2021.630396

Tuteja, N., Verma, S., Sahoo, R., Raveendar, S., \& Reddy, I. (2012). Recent advances in development of marker free transgenic plants: regulation and biosafety concern. Journal of Biosciences, 37, 167-197. https://doi.org/10.1007/s12038-012-9187-5

UIS (2019). Research and Development. UNESCO Institute of Statistics. Available online at: http://uis.unesco.org/en/topic/research-and-development [Accessed on 05-06-2021]

Van Eck, N. \& Waltman, L. (2011). Text mining and visualization using VOSviewer. In: Centre for Science and Technology Studies. The Netherlands: Leiden University.

Virgin, I., Bhagavan, M., Komen, J., et al. (2007). Agricultural biotechnology and small-scale farmers in Eastern and Southern Africa. Stockholm: Stockholm Environment Institute. 
Available online at: https://www.sei.org/publications/agricultural-biotechnologysmall-scale-farmers-eastern-southern-africa/ [Accessed on 05-06-2021]

Waltz, E. (2015). Nonbrowning GM apple cleared for market. Nature Biotechnology, 33(4), 326-7. https://doi.org/10.1038/nbt0415-326c

Watrud, L.S., Lee, E.H., Fairbrother, A., Burdick, C., Reichman, J.R., Bollman, M., Storm, M., King, G., \& van de Water, P.K. (2004). Evidence for landscapelevel, pollen-mediated gene flow from genetically modified creeping bentgrass with CP4 EPSPS as a marker. Proceedings of the National Academy of Sciences of the United States of America, 101(40), 14533-14538. https://doi.org/10.1073/pnas.0405154101

Watson, D. (2019). The use of genetically modified crops in developing countries. In: Genetically Modified Crops in Agriculture, ED -Tech Press, UK.

Wong, A.Y.T., \& Chan, A.W.K. (2016). Genetically modified foods in China and the United States: A primer of regulation and intellectual property protection. Food Science and Human Wellness, 5(3), 124-140. https://doi.org/10.1016/j.fshw.2016.03.002

Wu, F. (2006). Bt Corn's Reduction of Mycotoxins: Regulatory Decisions and Public Opinion. In: Just, R.E., Alston, J.M., \& Zilberman, D. (eds) Regulating Agricultural Biotechnology: Economics and Policy. Natural Resource Management and Policy, vol 30. Springer, Boston, MA. https://doi.org/10.1007/978-0-387-36953-2_9

Yan, S., Zhu, J., Zhu, W., Li, Z., Shelton, A.M., Luo, J., Cui, J., Zhang, Q., \& Liu, X. (2015). Pollen-mediated gene flow from transgenic cotton under greenhouse conditions is dependent on different pollinators. Scientific Reports, 5, 15917. https://doi.org/10.1038/srep15917

Zetterberg, C., \& Bjo“rnberg, K.E. (2017). Time for a new EU regulatory framework for GM crops? Journal of Agricultural and Environmental Ethics, 30, 325-347. https://doi.org/10.1007/s10806-017-9664-9

Zhang, C., Wohlhueter, R., \& Zhang, H. (2016). Genetically modified foods: a critical review of their promise and problems. Food Science and Human Wellness, 5(3), 116-123. https://doi.org/10.1016/j.fshw.2016.04.002

Zhang, W., Xu, X., Ming, C., Mao, Z., Shi, J. \& Xiang, Y. (2016). Surviving in the dispute: A bibliometric analysis of global GMF related research, 1995-2014. Scientometrics, 109, 359-375. https://doi.org/10.1007/s11192-016-1995-1

Zhong, S., Geng, Y., Liu, W., Gao, C. \& Chen, W. (2016). A bibliometric review on natural resource accounting during 1955-2014. Journal of Cleaner Energy Production, 139(c), 122-132. http://dx.doi.org/10.1016/j.jclepro.2016.08.039 
Search Documents (Grey + Scientific)

\section{Search Scenarios}

Perceptions on genetically modified food

Attitudes towards genetically modified food

Preference rates of genetically modified food

Consumer behaviour towards genetically modified food

Refined Documents

$\mathbf{N}=\mathbf{5 8 8}$

Limiting to Journal Articles

$N=543$

Limiting to 1981 to 2021 